\title{
An overall methodology for reliability prediction of mechatronic systems design with industrial application
}

\author{
Georges HABCHI and Christine BARTHOD \\ Univ. Savoie Mont Blanc, SYMME, F-74000, Annecy, FRANCE \\ Correponding author: georges.habchi@univ-smb.fr
}

\begin{abstract}
We propose in this paper an overall ten-step methodology dedicated to the analysis and quantification of reliability during the design phase of a mechatronic system, considered as a complex system. The ten steps of the methodology are detailed according to the downward side of the V-development cycle usually used for the design of complex systems. Two main phases of analysis are complementary and cover the ten steps, qualitative analysis and quantitative analysis. The qualitative phase proposes to analyze the functional and dysfunctional behavior of the system and then determine its different failure modes and degradation states, based on external and internal functional analysis, organic and physical implementation, and dependencies between components, with consideration of customer specifications and mission profile. The quantitative phase is used to calculate the reliability of the system and its components, based on the qualitative behavior patterns, and considering data gathering and processing and reliability targets. Systemic approach is used to calculate the reliability of the system taking into account: the different technologies of a mechatronic system (mechanics, electronics, electrical ...), dependencies and interactions between components and external influencing factors. To validate the methodology, the ten steps are applied to an industrial system, the smart actuator of Pack'Aero Company.
\end{abstract}

\section{Keywords}

Mechatronic systems, Reliability, Mission profile, Dependencies, Interactions, Modeling, Simulation.

\section{Introduction}

\section{Mechatronics}

The field of mechatronics has evolved as a highly powerful and most cost effective means for product realization. This is due to advances in microchip and developments in powerful computer technology including microprocessors, Application Specific Integrated Circuits (ASICs), computational techniques, that have bridged the gap between traditional electronic, control and mechanical engineering. Indeed, the development of mechatronic systems is a revolution for the industrial area, it affects a wide spectrum of fields such as manufacturing, transportation, energy and domestic devices. The field of transport and in particular the automotive sector is widely affected. The use of these systems is spreading rapidly and now reaches all sectors of the industry. Mechatronics has revolutionized the design and manufacturing of complex systems. In particular, its introduction in the automotive sector has deeply changed the development and manufacturing processes. Thus, a car is no longer conceived as a mechanical device that carries some electronic controls, but as a mechatronic system [Bertram et al, 2003], where the components of different technologies are fully integrated [DesJardin, 1996].

The term mechatronics was first proposed by an engineer from Yaskawa Electric Co. in Japan, in 1969, to designate the control of electric motors by computer [Yaskawa Electric, 1969]. This term has subsequently evolved and mechatronics gained legitimacy in academic circles with the publication of at least two dozens of definitions or descriptions in the literature. One such description is proposed by the international journal Mechatronics, published for the first time in 1991: "Mechatronics in its fundamental form can be regarded as the fusion of mechanical and electrical disciplines in modern engineering process. It is a relatively new concept to the design of systems, devices and products aimed at achieving an optimal balance between basic mechanical structures and its overall control " [Daniel 
and Hewit, 1991]. The international journal IEEE/ASME Transactions on Mechatronics [Onwubolu, 2005] created in 1996, proposes the following meaning: "Mechatronics is the synergetic combination of mechanical engineering with electronics and intelligent computer control in the design and manufacturing of industrial products and processes". The official definition of the Industrial Research and Development Advisory Committee of the European Community: "Mechatronics is the synergistic combination of precision mechanical engineering, electronic control and systems thinking in the design of products and manufacturing processes" [Comerford, 1994], [Grimheden and Hanson, 2001]. This definition is adopted by the technical committee on mechatronics formed by the International Federation for the Theory of Machines and Mechanisms, in Prague, Czech Republic [Leondes, 2000]. Whichever description is adopted, the general process and great significance of mechatronics are apparent. It establishes the multidisciplinary nature of mechatronics, which combines several sectors of different technologies in the designing and manufacturing of a product. Mechatronics is not inherently a science or technology: it must be regarded as an attitude, a fundamental way of looking at and doing things, and, by its nature, requires a unified approach [Millbank, 1993]. Ashley, then Alciatore and Histand also have summarized several definitions for Mechatronics [Ashley 1997], [Alciatore and Histand 2012]. Indeed, it can be said that Mechatronics relates to the design of systems, devices and products aimed at achieving an optimal balance between basic mechanical structure and its overall control. Particular importance must be attached to the aspects of innovation in mechatronics design philosophy which illustrate the benefits obtainable by an a priori integration of functionality with embedded microprocessor control (International Journal of Mechatronics). The synergy induced by mechatronic systems leads to an intelligent combination of technologies which leads to solutions with higher performance that cannot be obtained in separate applications. Then, it is important that the system is designed as a whole [Shetty and Kolk, 1997] [Breedveld, 2004].

The advent of mechatronic systems in industry has led to new constraints, such as: the incorporation of several technologies, the interactions between different functional entities, taking into account the dynamics of the system, the inability to perform exhaustive tests, etc. Despite these constraints, mechatronics brings undeniable benefits such as: cost reduction, customer satisfaction by the proposed innovative solutions, the positive response to societal demands increasingly important (pollution, consumption, safety) [Millbank, 1993], [Hewit, 1996], [Kortum et al., 1998], [Grimheden and Hanson, 2001], [Rzevski, 2003], [Ollero et al., 2006], [Isermann, 2007], [Yeong and Do Soon, 2015].

The most important concepts characterizing mechatronic systems are: re-configurability, dynamics, hybridity and dependency (interaction). A system is reconfigurable if it is intended to perform several functions alternately or perform a function by using its resources in several different ways. Indeed sometimes, a reconfiguration of the control system is carried out without interruption of the mission to ensure safety. It is under these conditions that the reconfiguration is dynamic [Moncelet, 1998], [Medjoudj, 2006]. The dynamics of the system lies in its aptitude to change its state during time. The presence of continuous phenomena and discrete events into the different states of the system characterize the hybrid concept. The dependency or interaction is described here by the effects produced by the action of a component to another component in the system changing its operating performances, in terms of degradation. Then, guarantee and security in terms of dependability and reliability becomes essential in the development of mechatronic systems [Rieuneau, 1993], [DesJardin, 1996], [Borner et al., 2002], [Demmou et al., 2004], [Schoenig, 2004], [Siemers et al., 2005].

\section{Reliability Design}

On the other hand, reliability has been increasingly used in firms over the last few years. This exponential use can be explained by the following reasons: safety improvement, failure and product lifetime control, customer satisfaction enhancement, maintenance improvement, product cost reduction, etc. The methods for analysis and evaluation of the reliability of a device are numerous [Lyonnet, 2012]. They are characterized according to three criteria: inductive or deductive, qualitative or quantitative, and tracked objectives. In inductive methods, we start with the causes to deduce the consequences, whereas in deductive methods we start with the consequences to infer the causes. In qualitative methods, the reliability is analyzed from a qualitative point of view to determine the modes of failures and risks, whereas quantitative methods seek to assign quantified value to reliability over time. Otherwise, according to the assigned objectives a reliability assessment method is chosen to make an objective 
analysis. This classification has a direct influence of the period of the lifecycle (design, manufacture, use) in the choice of the reliability method. Indeed, depending on the period in the lifecycle of the device, the reliability can be predicted, experimental (estimated) or operational (mission).

During the design phase, predicted reliability is mainly calculated using a mathematical model, based on a functional/dysfunctional decomposition of the system into subsystems and/or components and on the specific reliability of each. During the manufacturing phase, experimental reliability is assessed. Its calculation is based on the data processing of industrial testing, and on the finding of theoretical models / distributions (exponential, normal, gamma, Weibull ...) of the processing results. During the use phase, operational reliability is calculated. This is based on statistical processing of the data gathered from users (failure times) and on the findings of mathematical distributions. But also methods of reliability assessment can be categorized by technology area: mechanical, electrical, electronics, software, etc. For all these reasons, the evaluation of the reliability of a system, as multi-technological mechatronic system, is complex.

Thus, methods of reliability are numerous. Not limited to, the main methods include: fault trees, reliability block-diagrams, Failure Mode and Effects Analysis (FMEA), event trees, Markov chains, Petri networks, Bayesian networks, ... It is not a question here to describe all these methods, but the goal is to offer an overall methodology based on some of these methods. For indeed, it is clear that each of these methods is specific and cannot cover alone the whole field of reliability. Our investigation of the state of the art, concerns methodologies dedicated to complex or mechatronic systems.

Research in this area is still in the phase of development despite the few attempts in this direction [Ziegler, 1996], [Moncelet, 1998], [Mihalache et al., 2002], [Khalfaoui, 2003], [Guerin et al., 2003], [Schoenig, 2004], [Schoenig et al. 2006], [Mihalache, 2007], [Sadou, 2007], [Turki, 2008], [Demri, 2009], [Belhadaoui, 2011]. These methodologies are based on methods such as Petri nets, FMEA, Markov Chains and fault trees. In a recent article [Zhitao Liu et al., 2014], a method on the design and analysis of lithium-ion (Li-ion) battery pack from the reliability perspective is presented. The analysis is based on the degradation of the battery pack, which is related to the cells configuration in the battery pack and the state of health $(\mathrm{SoH})$ of all the Li-ion cells in the pack. Other studies, exist in the bibliography. They relate to methodologies based on Bayesian networks. For example, [Martins et al., 2013] proposed a study on the application of Bayesian networks to the human reliability analysis (HRA) of an oil tanker operation focusing on collision accidents. This study uses a four-phase methodology (familiarization, qualitative analysis, quantitative analysis, incorporation) to accomplish HRA [Swain $e t$ $a l .$, 1983] using the integration of fault trees and Bayesian networks [Droguett et al., 2007]. Also, to specify the reliability for new product development, [Murthy et al., 2009] developed a new model of product life cycle in which the life cycle was divided into eight phases and grouped into three stages (Predevelopment, Development, Post-development). [Peng et al., 2013] used this model for their study on life cycle reliability assessment of new products.

Among the methods dedicated to reliability, graph theory provides an appropriate tool to describe and graphically exploit the dependency relationships or independencies between variables. Probability theory brings, meanwhile, a formalism to quantify the dependency relationships by associating each variable a conditional probability law. Probabilistic graphical models, specifically Bayesian networks, initiated by Judea Pearl in the 1980s [Pearl, 1982] proved to be useful tools for representing uncertain knowledge and reasoning from incomplete information.

The graphical part of the Bayesian network indicates the dependencies (or independencies) between variables and gives a visual tool of knowledge representation, more easily comprehensible tool by its users. The use of probabilities can take into account the uncertainty in quantifying the dependencies between variables. Each node is associated with a conditional probability distribution that defines the probability of each of its values, knowing the values of the direct predecessor's nodes in the graph. [Pearl, 1986] and [Pearl, 2000] also showed that Bayesian networks allow to represent compactly the joint probability distribution on the set of variables.

Sometimes it is difficult or impossible to represent some systems with a fault tree or a reliability diagram. However, the concepts of minimum cuts and minimum success paths allow to fully define the relationships between the states of the system and the component states. 
G. Habchi and C. Barthod, An overall methodology for reliability prediction of mechatronic systems design with industrial application, Reliability Engineering \& System Safety, 155 (2016), 236-254, doi:10.1016/j.ress.2016.06.013

The paper presented by [Lin et al., 2015] undertakes a general reliability study using both classical and Bayesian semi-parametric degradation approaches. The goal is to illustrate how degradation data can be modelled and analyzed to flexibly determine reliability to support preventive maintenance strategy making, based on a general data-driven framework. The article proposed by [Mkrtchyan et al., 2015] is a review of applications and gaps on the use of Bayesian networks for human reliability analysis (HRA). The same authors suggest in a recent article [Mkrtchyan et al., 2016] some methods for building Conditional Probability Tables of Bayesian Belief Networks from limited judgment for HRA. In [Musharraf et al., 2016] the authors suggest in a recent article assessing offshore emergency evacuation behavior in a virtual environment using a Bayesian Network approach. In this paper [Foulliaron et al., 2015] some specific DBN structures are introduced in order to improve the degradation modeling and perform reliability analysis, integrating the concept of conditional sojourn time distributions that allow considering simultaneously several degradation dynamics.

The analysis of different approaches used to study the reliability for mechatronic systems, enabled us to identify some lacks of reliability for these systems:

- The various phases of operation of a mission profile, are not taken into account, therefore there is no mission profile built on these phases.

- The physical and functional interdependencies generated between the different technological parts are not studied.

- An evaluation of the overall reliability of the system does not exist.

In more detail, Table 1 summarizes the studied points and gaps in relation to certain criteria or items we considered relevant to the achievement of the methodology. "+" sign indicates that the item was considered by the used methodology while the "-" sign indicates that it was not.

Table 1. Synthetic analysis of the state of the art according to certain criteria

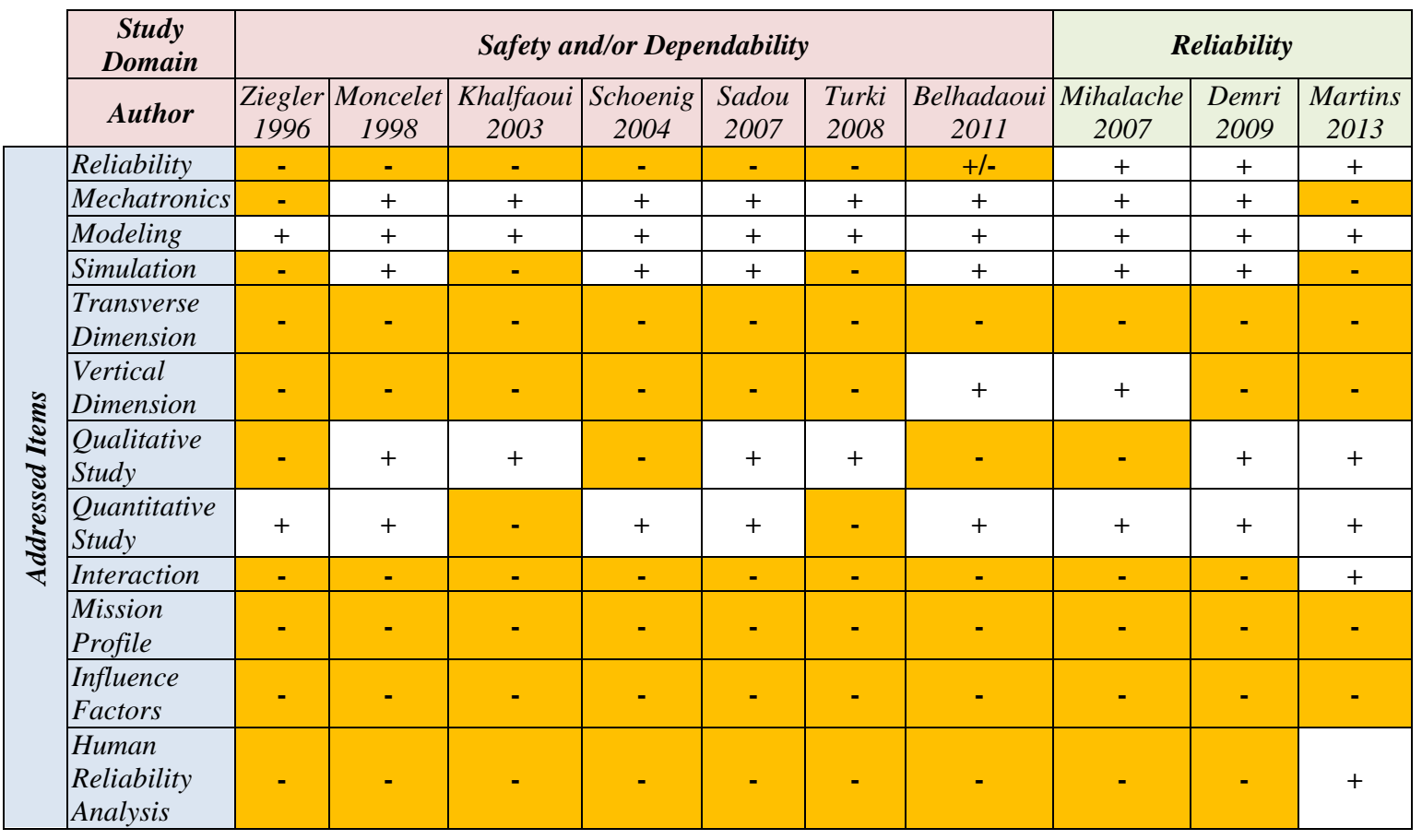

Besides the listed lacks (mission profile, interdependencies, overall reliability) and which we seek to answer, the proposed methodology makes some improvements:

- The analysis of the physical location of the components which allows identification of collateral failures in addition to intrinsic functional failures and shortcomings identified by organic architecture.

- The dysfunctional analysis using FMEA enriched by the classification of defects according to their nature, their establishment speed and amplitude. 
- The analysis of interdependencies by building the interactions matrix.

- Modeling and simulation with consideration of the mission profile and interactions.

Therefore, our goal is to provide an overall methodology for assessing the reliability of a mechatronic system as a whole and taking into account: the technology sectors, the phase of the lifecycle, and the application field wherein the product is immersed.

The paper is organized as follows: section 2 presents the overall ten-step evaluation methodology: section 3 introduces an application to a case study of an industrial project and concentrates on results analysis, and section 4 summarizes the findings from the study.

\section{Proposed overall methodology}

\section{The V-Cycle}

To meet the challenges of quality, cost and time constraints imposed by the market, a new approach for system design is necessary to enable the safe integration of different technologies. This approach should definitely consider the goals of reliability and safety from the design phase of the device.

Before discussing the methodology, we propose a common definition of a (complex, mechatronic, etc.) system. Such a system can be described as a set of interacting elements among themselves and with the environment whose behavior depends on:

- Individual behavior of its components,

- Rules of dependencies and interactions between elements (interfaces, algorithms, protocols),

- The topological organization of the elements (architectures).

Complex industrial systems are characterized by the fact that they result from a combination of subsystems of different technologies. The V-cycle was first used as a model of development in different technologies: mechanical [Tollenaere, 1998], electronics [Molla et al., 2004] and software [Gaudel et al., 1996]. It was then generalized to the development of complex systems, particularly mechatronic systems to have a common terminology and propose an overall methodology with shared stages to the different technologies. There are other types of development cycles, the best known being the cascade or spiral cycles.

The development model according to the V-cycle (Fig. 1) organizes the different phases of development, from specification to product validation [DesJardin, 1996], [Isermann, 2007]. The V-cycle is characterized by a horizontal axis representing time and a vertical axis representing the level of integration of the system. It can be described as a succession of five phases having an integration degree that evolves over time: analysis / specification, design, implementation / manufacturing, verification and validation. For a mechatronic system, the major difficulty is the translation of the system specification into specifications for each component with different technologies [Rieuneau, 1993], [DesJardin, 1996]. The complexity of the system and the interpretation of specifications by different teams, are particularly sensitive to be taken into account in the design phase. When developing a system, the manufacturer specifies not only the functionality but also the objectives in terms of dependability. Thus, it is increasingly necessary to integrate security into the operating system approach, very early in the project, in the first phase of the development cycle [DesJardin, 1996]. This integration leads not only to multiply the studies of reliability, availability, maintainability and safety, but also to develop a collaborative methodology that promotes their inclusion in projects and through the different communities related to the development of mechatronic systems. 
G. Habchi and C. Barthod, An overall methodology for reliability prediction of mechatronic systems design with industrial application, Reliability Engineering \& System Safety, 155 (2016), 236-254, doi:10.1016/j.ress.2016.06.013

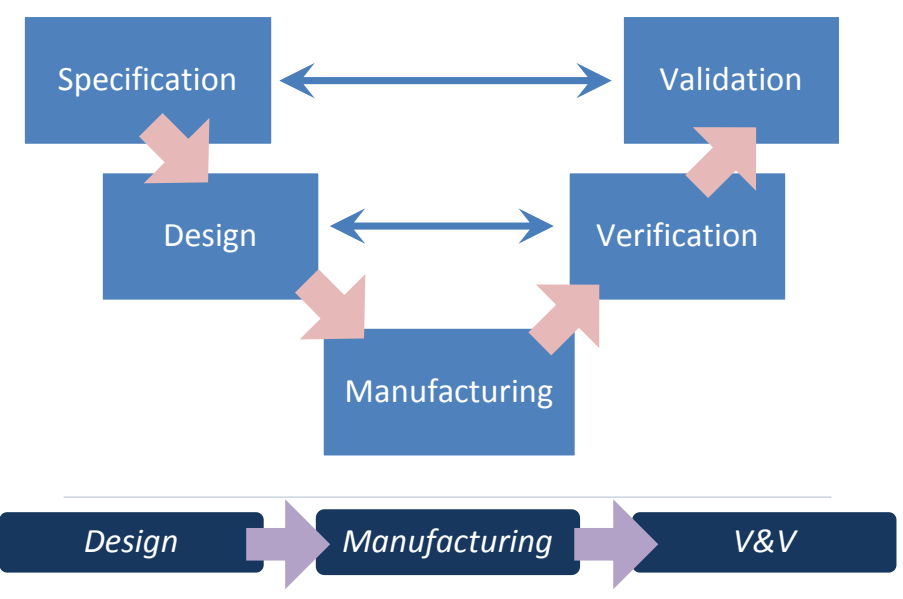

Fig. 1. The V-cycle

\section{Overall ten-step methodology}

Thus, the methodology presented in Fig. 2 shows all the steps to consider during the downward phase of the $\mathrm{V}$-cycle, when designing a mechatronic product. The ten main steps are organized into two stages. The first one is to deploy qualitative analysis while the second provides a quantitative analysis of the product reliability.

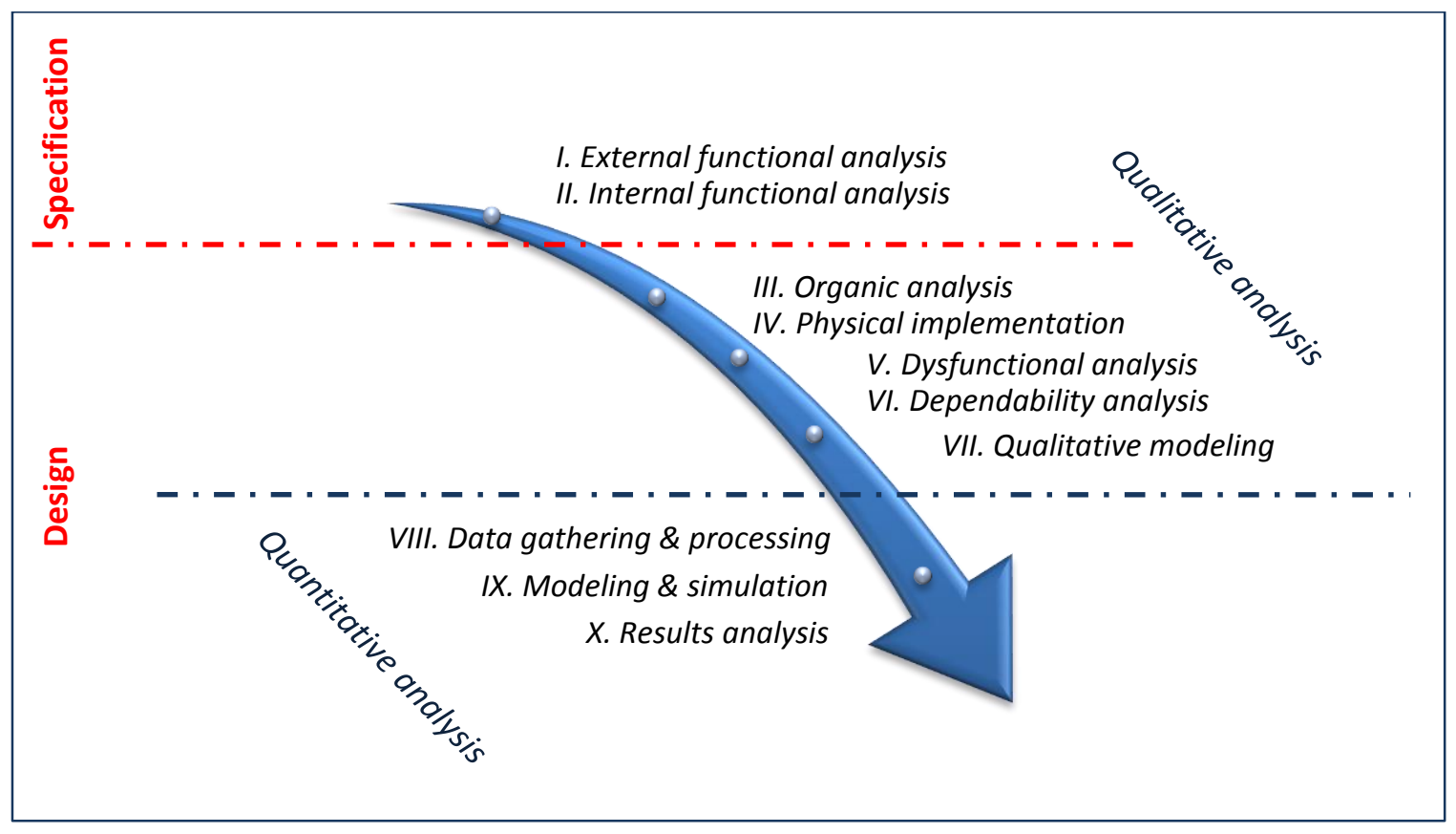

Fig. 2. Proposed Overall Methodology evaluating the predictive reliability of mechatronic systems 
G. Habchi and C. Barthod, An overall methodology for reliability prediction of mechatronic systems design with industrial application, Reliability Engineering \& System Safety, 155 (2016), 236-254, doi:10.1016/j.ress.2016.06.013

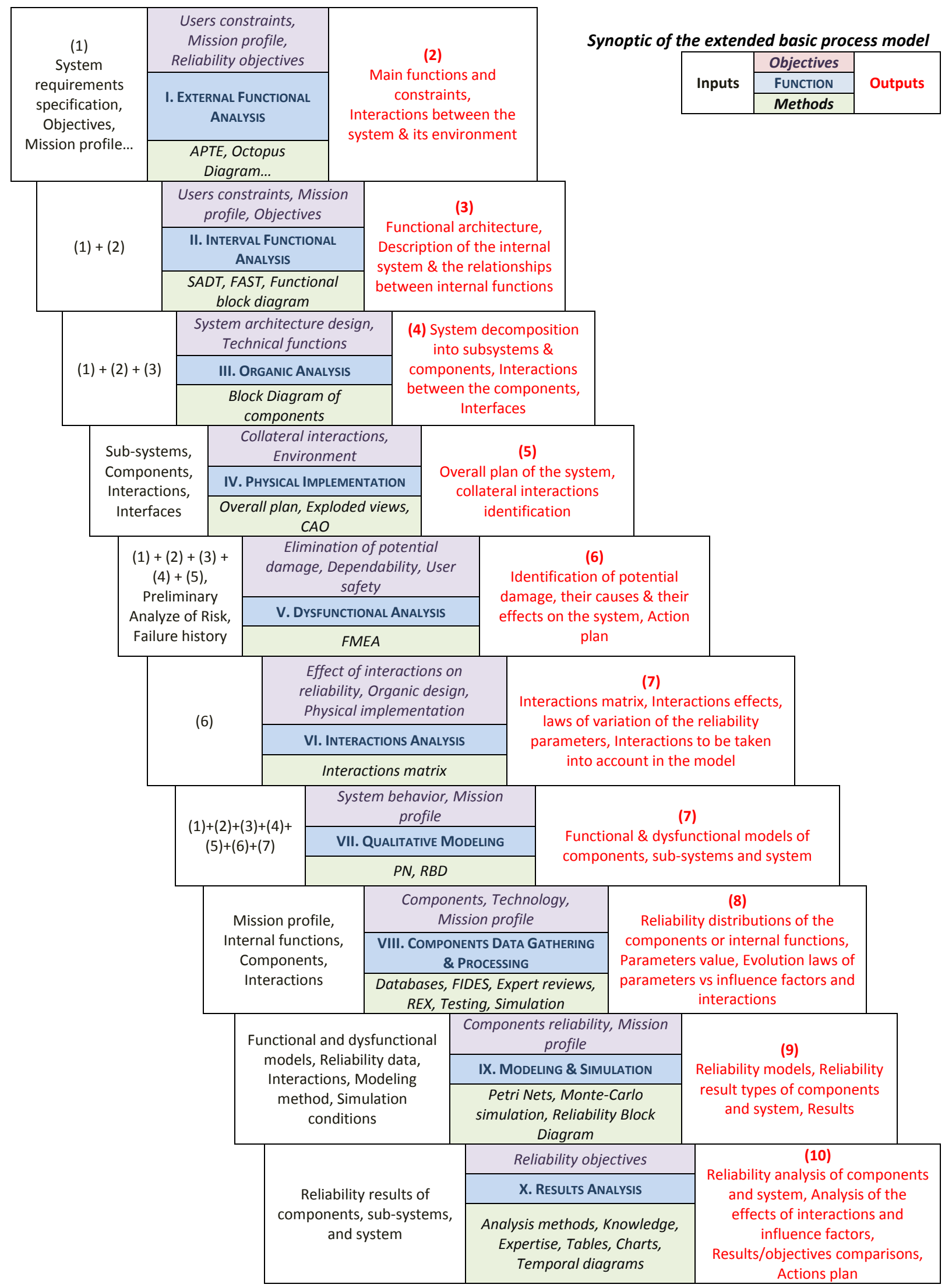

Fig. 3. Proposed Overall Methodology (Functions: Inputs, Objectives, Methods, Outputs) 
Fig. 3 presents an overview of all steps with a summary of the inputs, outputs, objectives and methods associated with each step. Each step is based on the basic process model (Fig. 3) which can be seen in any function or activity and represents a balance of energy going into a process and coming out. This model is extended in order to appear the objectives and the methods / tools used for a given function. The ten steps of the overall methodology are presented in detail in the following paragraphs.

It is important to note that in a conventional design process of new products, analysis methods such as external functional analysis, internal functional analysis, risk analysis, FMEA, ... are used. However, these methods are used separately by different people. They are not necessarily associated in a unique and overall process and do not reflect necessarily reliability problems. So the proposed methodology aims to structure the process of analysis and evaluation of reliability in order to be considered at the earliest stages of design. The analysis part is not necessarily increased, but it is rather better organized. Nevertheless, for whatever the considered system, one of the main difficulties in its reliability evaluation is to identify the dominating elements in terms of reliability. A mechatronic system is generally composed of numerous components. Most of the time, only feedback and experience can help to select the relevant elements, in terms of reliability evaluation. Moreover, it seems important to list all the components in order to be able to identify the interactions. Consequently, to reduce the calculations, the selection of the dominating components should be done only after the step IV "interactions analysis".

\subsection{External functional analysis}

A function can be defined as the action of an entity or one of its components expressed in terms of purpose. It is necessary to distinguish the functions and the structure (or hardware architecture support).

For simple or complex systems, a basic principle used in analysis, is to divide and conquer. This means to apprehend the overall system, partition it into subsystems (components) and then try to understand each subsystem (component) and its relationships (external and internal).

The APTE (APplication des Techniques d'Entreprise / Application of Corporation (Professional) Methods) method was created by Gilbert Barbey in 1964 [Bertrand de la Bretesche, 2000]. It is a method of functional analysis and value analysis to conduct innovation and optimization projects. The first tool of the APTE method is a chart of benefits also called "horned beast". Its use allows identifying the purpose of the study. The second one is the "octopus diagram" or "interactions graph". It is used as a tool illustrating the relationship between the system and its environment. It allows highlighting the main functions and constraints functions for the system. The following points are realized at the external functional analysis (EFA) step [Lyonnet, 2006]:

- Identification of the purpose of the study,

- Identification of the components of the external environment,

- Identification of the main functions and constraints functions,

- Characterization of the main functions and constraints functions,

- Definition of the mission profile of the system, that means the conditions of use in terms of temperature, vibration, humidity...

\subsection{Internal functional analysis}

The internal functional analysis (IFA) identifies the internal functions that are necessary to achieve the main functions of the system, taking into account the constraints functions identified at the previous step. An internal functional description can usually be done either by function or to a given level. A description of each level is a hierarchical tree. There are several methods to achieve this analysis. We include for example, SADT, FAST, Functional tree, functional block diagram, etc.

The Functional Block Diagram (FBD) is a tool used to map the key internal functions and the relationships between these functions. The FBD usually leads to a Functional Analysis Table (FAT) for synthesizing all data. 
The IFA establishes relationships between the EFA and possible solutions to meet the need. It allows the definition of the functions identified into internal technical functions. In addition, the FAT supplies some selection criteria to compare objectives between different solutions.

\subsection{Organic analysis}

The objective of the organic analysis (OA) is to define the architecture of the system, the decomposition into sub-systems and components, and the identification of the functional interactions between the different elements of the system. The term interaction is defined here as a functional dependence between the components of the system producing a change in the reliability of the system. The $O A$ is built according to the following points [CETIM, 2007]:

- Definition of the components associated with the internal functions

- Decomposition of the system into subsystems and components

- Design of the organic system architecture

- Identification of the functional interactions between the components of the system (functional interactions matrix)

- Identification of the collateral interactions between the components of the system (physical location of the components).

\subsection{Physical implementation}

Physical location or Implementation (PI) aims to identify possible collateral damage among the different elements of the system to identify principally second type of failures, which are caused by the operation or the failure of another contiguous component of the system. It allows visualizing the locations of the parts or organs. It highlights the physical proximity of components and collateral interactions that may result.

Therefore, it identifies one or more collateral interactions between two components due to changes in environmental parameters such as temperature, vibration... which could generate second type of failure, directly produced by another part of the system.

\subsection{Dysfunctional analysis}

The objective of the dysfunctional analysis is to identify the dysfunctional failure modes and degradation of the system components and then analyze their effects on the system. To achieve this analysis, the outputs of the functional and organic analyzes are needed.

The main methods used in a dysfunctional analysis are: the Preliminary Risk Analysis (PRA), Failure Modes, Effects and Criticality Analysis (FMECA), Analysis of the Effects of Software Errors (AEEL), Trees Failures (ADD), etc. [Mihalache et al., 2002], [Guenzi, 2010]. Except the AEEL method that is dedicated to software, the other methods are used for technologies such as mechanical, electronic, electric, etc.

Failure Modes and Effects Analysis (FMEA) is one of the first systematic approaches to analyze failures [Villemeur, 1988], [Villemeur, 1997]. It was developed by the U.S. Army and is in the first guideline Military Procedure MIL-P-1629 "Procedures for performing a failure mode, and effects analysis" of 9 November 1949. Thereafter, it was developed by the aerospace industry in mid 60s. The FMEA analysis describes inherent causes of events that lead to system failure, determines their consequences, and formulates methods to minimize their occurrence or recurrence. Therefore, it allows identifying the critical elements of security (causing critical or catastrophic events) and dormant faults.

There are basically two types of FMEA: design and process FMEA.

Design FMEA is used to evaluate the failure modes and their effects for a product before it is released to production. It is usually applied at the component and subsystem levels. Its objectives are:

- To identify failure modes and rank them according to their effects on the product performance, 
G. Habchi and C. Barthod, An overall methodology for reliability prediction of mechatronic systems design with industrial application, Reliability Engineering \& System Safety, 155 (2016), 236-254, doi:10.1016/j.ress.2016.06.013

- To identify design actions to eliminate potential failure modes or reduce the occurrence of the respective failures,

- To document the rationale behind product design changes.

Process FMEA is used to analyze manufacturing and assembly processes. Its objectives are to identify:

- Failure modes that can be associated with manufacturing and assembly process deficiencies,

- Highly critical process characteristics that may cause the occurrence of particular failure modes,

- Sources of manufacturing/assembly process variations.

However, it is important to mention some limitations of FMEA:

- Limited insight into probabilistic system behavior,

- FMEA is performed for only one failure at a time. There may be multiple failure modes with comparable likelihoods,

- Limited insight into the functional relationships between components,

- Time element in system operation cannot be represented.

FMEA is the main method used for dysfunctional analysis. To meet certain limitations, additional information has been added to specify the type of failure (intrinsic, collateral, and functional), its nature (first or second), its establishment speed (sudden or progressive) and its amplitude (partial or complete). Also, this enriched FMEA being realized, the interactions matrix between the components and, the qualitative and quantitative modeling, fill the other gaps. Finally, the formalization and the analysis of the physical implementation of the components highlight the failure modes issued from collateral interactions (second nature mode), that are not usually identified.

\subsection{Dependence analysis of interactions}

Compared to a conventional design approach, we propose here an additional analysis of the dependencies between system components in order to identify potential interactions. This step aims to:

- Identify interactions defined and classified in the enriched FMEA (a criticality analysis will be necessary).

- Allow to make the choice of interactions to be considered in modeling the system in terms of reliability.

The interactions between components of a mechatronic system are identified from its organic architecture for functional interactions and the physical implementation of the system components for the collateral interactions.

The identified interactions can be transcribed in a component / component matrix (Table 2) allowing a visual analysis of their classification. Each component may act on another component. To improve the readability of the matrix of interactions, we propose to adopt the following notation: UF for unidirectional functional interaction, $\mathrm{BF}$ for bidirectional functional interaction, UC for unidirectional collateral interaction and $\mathrm{BC}$ for bidirectional collateral interaction. 
G. Habchi and C. Barthod, An overall methodology for reliability prediction of mechatronic systems design with industrial application, Reliability Engineering \& System Safety, 155 (2016), 236-254, doi:10.1016/j.ress.2016.06.013

Table 2. Dependence matrix between components (interactions)

\begin{tabular}{|c|c|c|c|c|c|c|c|}
\hline \multirow[b]{2}{*}{ Acts on } & & \multicolumn{3}{|c|}{ Sub-system 1} & \multicolumn{3}{|c|}{ Sub-system 2} \\
\hline & & Comp 1 & Сотр 2 & Comp 3 & Comp i & Comp $k$ & Cотр $n$ \\
\hline \multirow{3}{*}{$\begin{array}{c}\text { Sub- } \\
\text { system } 1\end{array}$} & Comp 1 & & $U F$ & & $B F$ & & \\
\hline & Comp 2 & & & & & & \\
\hline & Comp 3 & & & & & & \\
\hline \multirow{3}{*}{$\begin{array}{c}\text { Sub- } \\
\text { system } 2\end{array}$} & Comp $i$ & & & & & $U C$ & \\
\hline & Comp k & & $B C$ & & $U F$ & & \\
\hline & Comp $n$ & & & & & & \\
\hline
\end{tabular}

A thorough analysis must be carried out on all the identified interactions in order to surround their effects in the reliability evaluation of the system. Thus, it is important to identify the interactions causes as they probably influence the defined using conditions (temperature, vibration, shock...) or the intrinsic functioning of the system (friction, heating, wear...). The influent factors being identified; the main difficulty of the approach is to quantify how the reliability laws of the interactive components may be modified.

\subsection{Qualitative modeling}

The objective of qualitative modeling is to model the functional and dysfunctional behavior of the system and its components. Achieving this analysis depends on all analyzes carried out previously. The deployment of FMECA method, enhanced by the classification of failure modes of components depending on their nature (first or second), their establishment speed (sudden, progressive) and their amplitude (partial or complete) allows us to introduce new failure modes and additional states. Indeed, the failure modes commonly used in modeling are intrinsic failure modes of components (failure of first type as classified by nature). To take into account the interactions inducing collateral damage, the failure modes of second type was added.

\section{Petri nets}

The most appropriate methods for modeling of mechatronic systems are state-transition models such as state graphs (Markov graphs, Bayesian networks) and approaches based on Petri nets [Bertram et al. 2003]. Petri nets can be used for modeling the functioning and non-functioning states of complex systems [Charki et al. 2009]. This method provides a convenient graphical representation of a placetransition net which consists of: places (circles) which model states, tokens (black dots) which represent the specific value of the states, transitions (rectangles) which model activities/events that change the values of states, and arcs which specify the interconnection of places and transitions thus indicating which states are changed [David et Alla, 1992], [Daniel, 1995], [Dutuit et al., 1997].

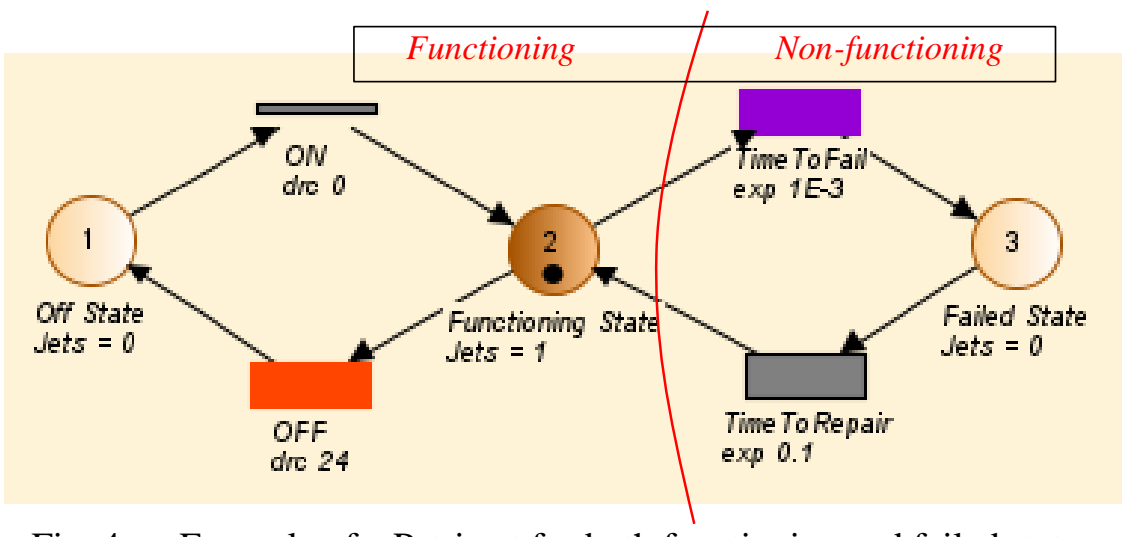

Fig. 4. Example of a Petri net for both functioning and failed states 
However, some generic tools and their implementation could form an obstacle to their deployment in the industry. Despite this barrier, for qualitative modeling of mechatronic systems, we can use Petri nets because they allow:

- Modeling of all integrated technologies,

- Compatibility with all stages of the V-cycle,

- Analyzing functional and dysfunctional behaviors,

- Modeling continuous and discrete events (hybrid systems),

- Taking into account the dynamic behavior of the system,

- Modifying their internal structures (re-configurability),

- Specifying interactions between the components.

\section{Reliability Block Diagrams}

Using a Reliability Block Diagram (RBD), a qualitative analysis of reliability is to structure the system and then calculate the combination of components that leads to system failure. To express the combination of components causing the failure, analysts use two concepts: the paths to success and cuts.

Fig. 5 shows an example of an RBD with success paths and cuts.

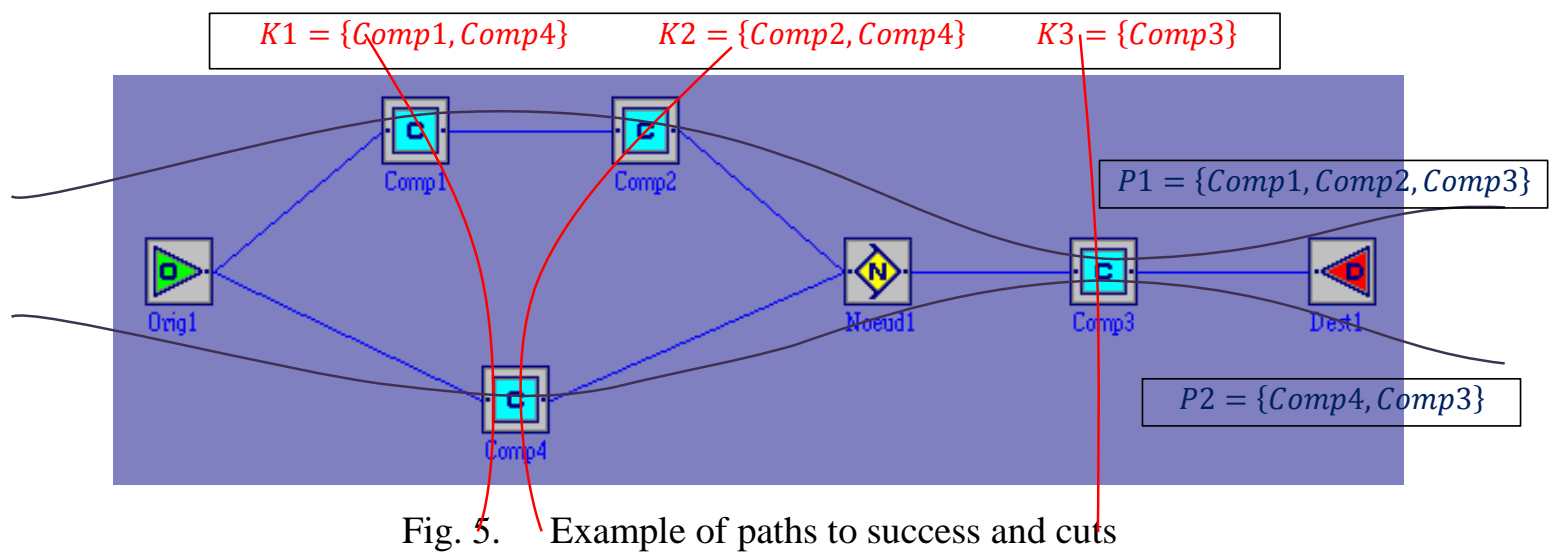

The set of components of a system of order $n$ is $C=\{1,2,3, \ldots, n\}$.

A path to success set, $P$, is a subset of $C$ which by functioning ensures that the system is functioning. A path set is minimal if it cannot be reduced without losing its status as a path set (it contains no subpath).

A cut set, $K$, is a subset of $C$ which by failing causes the system to fail. A cut set is minimal if it cannot be reduced without losing its status as a cut set (if removing any component in the list, the system is not faulty). The size (or order) of the cut is the number of elements in the list. Knowledge of minimum cuts used allows establishing qualitatively the list of critical components from the functional organization of the system.

The structure function for an RBD is a function $\emptyset\left(x_{1}, x_{2}, \ldots, x_{n}\right)$ associated with a given system, such that $x=\emptyset\left(x_{1}, x_{2}, \ldots, x_{n}\right)$ where $x_{i}$ denotes the state of component or subsystem i and $x$ denotes the state of the entire system. For $x_{i}=1$ the component or subsystem is functioning and for $x_{i}=0$ it is failed. For $x=1$ the system is functioning and for $x=0$ the system is failed.

\subsection{Data gathering and processing}

The objective of this step of the methodology is to identify the distributions of reliability (lifetime distributions) associated with the components and then gather, and process the data in order to calculate their parameters values. Generally, for simplicity in reliability calculation, it can be assumed that the equipment is in a constant hazard rate phase of the bathtub curve, where failure rate $\lambda$ is constant and the failures are independent of time and will not increase or decrease with the age of the equipment. We consider this hypothesis to the electronic technology since several databases exist. The most used ones 
G. Habchi and C. Barthod, An overall methodology for reliability prediction of mechatronic systems design with industrial application, Reliability Engineering \& System Safety, 155 (2016), 236-254, doi:10.1016/j.ress.2016.06.013

are FIDES, MIL-HDBK 217F, and RDF 2000. Indeed, the most suited distribution for this technology is exponential. And it is quite easy to calculate the failure rate or Mean Time Between Failures (MTBF) taking into account several factors. For other technologies, databases are available for some standard components but are very limited. The experiment is essential for these technologies and achievement of tests in site is often necessary. In some cases, tools such as simulation or expertise are used. However,

Table 3 presents some of the main reliability (failure) distributions used to evaluate the reliability of components and the associated parameters for some types of technology. The reliability distribution is defined once its parameters are identified (the exponential model depends on failure rate $\lambda$. The normal and lognormal models depend on average $\mu$ and standard deviation $\sigma$, and the three-parameter Weibull model depends on shape parameter $\beta$, location parameter $\gamma$ and scale parameter $\eta$ ).

Table 3. Reliability distributions associated with the technology of components

\begin{tabular}{ccc}
\hline Technology & Reliability distribution & Parameters \\
\hline Electronic, Electrical & Exponential & $\lambda$ \\
Mechanical [Doyle, & Weibull & $\beta, \eta, \gamma$ \\
1991] & Normal, Lognormal & $\mu, \sigma$ \\
Software & Exponential & $\lambda=\mathrm{kpN}_{0}$ (Musa model) [Musa et al., 1987] \\
\hline
\end{tabular}

With:

$\lambda$ : Failure Rate

$\beta$ : Shape Parameter

$\eta$ : Scale Parameter

\%: Position Parameter

$\mu$ : Mean

б: Standard Deviation

$k$ : Constant depending on the dynamic structure of the program

$p$ : Number of executions per time unit

$N_{0}$ : Initial number of faults in the program

\section{Calculating the failure rate of electronic components using FIDES database}

The expression of the failure rate depends on several factors: design technology, manufacturing technology and environmental operation of the component. Then, according to FIDES, the failure rate depends on a basic failure rate of the component, weighted by factors of technology, design, manufacture, use, environment, etc. [Demri, 2010]. The failure rate can be written as follows:

$$
\lambda=\lambda_{\text {Physical }} \times \Pi_{\text {Part_Manufacturing }} \times \Pi_{\text {Process }} \times \Pi_{R F-H F} \times \Pi_{H-M} \times \Pi_{L F}
$$

Where:

$\lambda:$ Predicted failure rate

$\lambda_{\text {Physical }}$ : Physical failure rate (Represents the physical contribution)

$\Pi_{\text {Part_Manufacturing: Reflects the quality and technical control of component manufacturing }}$

$\Pi_{\text {Process: }}$ : Reflects the quality and technical control of the processes of developing, manufacturing and use of products containing the component

$\Pi_{R F-H F}$ : Reflects the quality and control of the radiofrequency $(R F)$ or high frequency $(H F)$ product lifecycle

$\Pi_{H-M}$ : Reflects the quality and control of design and manufacturing of hybrid or MCM (Multi-Chip Modules)

$\Pi_{L F}:$ Reflects the transition factor to lead-free processes

Along with FIDES, the failure rate of electronic components is calculated according to the following 3 steps: 
- Defining the mission profile information (phases, duration, temperature, humidity, vibration, etc.)

- Calculating the values of $\Pi$ factors $\left(\Pi_{\text {Process }}, \Pi_{\text {Part_Manufacturing }}, \Pi_{\text {Placement }}, C_{\text {Sensivity }}\right.$, $\left.\Pi_{\text {Application }}, \Pi_{\text {Ruggedising }}, \Pi_{\mathrm{RF}-\mathrm{HF}}, \Pi_{\mathrm{H}-\mathrm{M}}, \Pi_{\mathrm{LF}}\right)$

- Calculating the failure rates (EASYREL tool).

It seems important to emphasize the problem of the data gathering. Indeed, an efficient modeling will provide bad results if the feeding data are not relevant. As far as predictive reliability is concerned, the main limit of the methodology is the lack of reliable data, in particular concerning mechanical parts where no database exists. So, this step has to be carried out and validated jointly by the analysts and the industrials.

\subsection{Analytic calculation, modeling and simulation}

The objective of this step is to evaluate the reliability function for the system and its components (sub-systems) over time and according to the mission profile of the system. A system's overall reliability can be determined by the development of reliability models. The complexity of these models is dependent upon various factors such as mission profiles (usage profiles), function criticality, redundancy characteristics, interactions between components, etc. The general approach is to capture the modeling effort with the use of graphical methods such as Reliability Block Diagrams, Petri Nets, Markov Chains, etc.

Two methods are used into the proposed methodology:

- Petri Nets for behavioral modeling (functional and dysfunctional) and Monte Carlo simulation for convergence of results

- Modified Reliability Block Diagrams, adapted in order to take into account the mission profile and the considered interactions for analytical calculation.

The comparison of the results obtained by both methods is necessary to verify and validate on the one hand, Petri nets model and the parameters chosen for simulation, and on the other hand, the calculation method developed in the context of reliability block diagrams considering the mission profile and interactions.

\section{Petri nets modeling and Monte-Carlo simulation}

Carl Adam Petri has proposed in his thesis (1962), a new tool dedicated to the modeling of controllers. Following this work, Petri nets have undergone several extensions. Among other developments, in the 80s, J.P. Signoret and A. Leroy used Petri nets as behavioral models to perform Monte Carlo simulations (for large systems). Much research is being done on the subject, including MOCA-RP tool [Marsan et al. 1994], the SHARPE Software Package [Sahner et al., 1996], [Trivedi, 1982], [Wang et al., 1993], [Goševa-Popstojanova et al., 2001].

Petri nets are a good tool to model the dysfunctional behavior of a system. It is well-adapted to understand the various failures and their impact on the system. As a reminder, a Petri net is a directed graph with two types of nodes: places (states or conditions) represented by circles and transitions (or events) symbolized by bars. These nodes are interconnected by directed arcs of places to transitions (upstream arcs) and transitions to places (downstream arcs) exclusively. Circulating tokens (indivisible markers), symbolizing the presence in a given instant of information or any special initialization to places where they reside, allows dynamic modeling of system behavior (both desired and unwanted) to within the network. A stochastic Petri net (or in our case reliability net) is an extended Petri net as it associates with each transition a period of random or deterministic firing (zero or not). If the deterministic period is 0 , it is called immediate transitions. A complete presentation can be found in the book [Marsan et al. 1994]. 
The quantitative evaluation of a Petri net is usually done either by processing the Markov model available from the marking graph of the Petri net, each non-vanishing marking corresponding to a state of the Markov chain, or by animating Monte-Carlo simulation directly on Petri net and not its reachability graph model. The principle of Monte-Carlo consists in playing a number of scenarios of evolution of the Petri drawing pseudo-random delays associated with transitions and making statistics values with an interest such as the number of shots for a transition, the average residence time in one place, etc. Disadvantages of this approach involve the accuracy of the variable that depends on the number of simulations thus the processing time is long and potentially can hardly be applied to rare events. The two main structures are: the simulation clock that records the mission time for a simulation, and the list of events that are held in a chronological order. The events occurrence dates are randomly generated according to their probability distributions. The simulation then proceeds as follows: (i) choose the most recent event for execution, (ii) run the event and then remove it from the list, (iii) update data (list of events, observation variables, etc.), (iv) advance the clock to the date of the next event, (v) stop simulation if one of the following two conditions is true: the simulation mission time is exceeded, the event list is empty.

\section{Reliability Block Diagrams}

Historically, the diagram method of reliability or success is the first to have been used to analyze systems. An RBD also known as a Dependence Diagram (DD) is a graphical representation of the components of the system and how they are reliability-wise related. The diagram represents the functioning state (i.e., success or failure) of the system in terms of the functioning states of its components. To define the reliability characteristics of each component, we can use software to calculate the reliability function for the entire system and obtain a wide variety of system reliability analysis results, including the ability to identify critical components and calculate the optimum reliability allocation strategy to meet a system reliability goal.

Using an RBD, a quantitative analysis of reliability allows structuring the system, assigning the probabilities of failure of basic blocks, and then assessing the probability of failure of the entire system.

An RBD or DD provides a success oriented view of the system, a framework for understanding redundancy, facilitates the computation of system reliability from component reliabilities. An RBD is drawn as a series of blocks connected in parallel or series configuration. For punctual reliability computing, each block represents a component of the system with a failure rate $(\lambda)$ or a Mean Time Between Failures (MTBF). For temporal reliability computing, each block represents the parameters of failure or reliability distribution (exponential, normal, lognormal, Weibull, etc.). Parallel paths are redundant, meaning that all of the parallel paths must fail for the parallel network to fail. By contrast, any failure along a series path causes the entire series path to fail. An RBD may be converted to a success tree (ST) by replacing series paths with AND gates and parallel paths with OR gates. A success tree may then be converted to a fault tree (FT) by applying de Morgan's theorem.

In order to evaluate RBD, closed form solution is available in the case of statistically independence among blocks or components. Where the statistically independence assumption is not satisfied, specific formalisms and solution tools, such as Dynamic RBD [Distefano and Puliafito, 2009], have to be considered. DRBD is a powerful notation to model system reliability, derived from RBD. If the components of a DRBD are independent, it can be analyzed by applying the combinatorial structure equations [Rausand and Høyland, 2003], obtaining the total reliability function analytically. Unfortunately, the combinatorial/analytic method cannot be extended to DRBD models.

\section{Modeling of interactions}

Statistically dependent failures are defined as events in which the probability of each failure is dependent on the occurrence of other failures. In general, statistically dependent failures are handled using Dynamic Methods such as Markov models, Petri nets, Dynamic Reliability Block Diagrams, etc. However, in systems with redundant identical components static techniques may be used, for a generalization of the $\beta$ factor method and other methods see [Rutledge and Mosleh, 1995]. $\beta$ factor can be interpreted as the probability that component failure occurs to a common cause event. The $\beta$ factor 
method is an approximation method used for the quantitative evaluation of Common Cause Failures (CCFs) that are single faults resulting in the failure of multiple components. Typical examples include impact, vibration, temperature, contaminants, miss-calibration, improper maintenance, etc.

In a recent study [Sanna Lahokallio et al. 2015], the effects of different temperature cycling profiles were studied by altering temperature ranges, extreme temperatures, soak times to extreme temperatures and transition times between extreme temperatures. It was observed that the different temperature cycling profiles affected the failure mechanisms detected. Also in another recent study [Yeong K. Kim and Do Soon Hwang, 2015], the authors investigated Plastic Ball Grid Array (PBGA) packaging reliability assessments under random vibrations for space applications. Then, the specimens were undergone severe random vibrations with two different levels of 22.48 root mean square acceleration (grms) for one minute, and 31.78 grms for two minutes.

A $\beta$ factor is estimated such that $\beta \%$ of the failure rate is attributed to the CCF and $(1-\beta) \%$ to the random failure rate of the component [Mosleh et al, 1998]:

Where:

$$
\begin{gathered}
\text { (1) } \lambda_{T}=\lambda_{C}+\lambda_{I} \\
\text { (2) } \lambda_{C}=\beta \lambda_{T} \\
\text { (3) } \lambda_{I}=(1-\beta) \lambda_{T}
\end{gathered}
$$

$\lambda_{T}$ is the total failure rate

$\lambda_{C}$ is the common cause failure rate

$\lambda_{I}$ is the independent failure rate

A point estimate for $\beta$ is given by:

Where:

$$
\text { (4) } \beta=2 n_{C} /\left(n_{I}+2 n_{C}\right)
$$

$n_{I}$ is the number of independent failures

$n_{C}$ is the number of common cause failures

The internal functional analysis is needed to establish the model (RBD or PN). Indeed, the system may perform more than one function at the same time but also, a function may be performed by more than one set of components. The mission profile is a multi-mode mission. The operating conditions of the system change in successive phases of mission although the basic physical configuration of the system remains the same. Thus, component failures affect system failure, depending on phase and operational conditions at the time. The consequence for the model is that different phases might represent different reliability configurations. This situation cannot be depicted accurately using basic RBDs and changes have to be made to address this modeling problem.

Analytic methods and modeling and simulation are organized according to the following three points: (i) Implementation of the quantitative models according to the qualitative analysis, (ii) Reliability calculation without interactions consideration, (iii) Reliability calculation considering interactions and hypothesis.

\subsection{Results analysis}

The objective of the results analysis step is the establishment of a final report which analyzes and discusses the results in terms of reliability. The objectives considered in the first step of the methodology are compared with the results obtained. Proposals are then submitted to make the changes if it is proved necessary to improve reliability and achieve the objectives.

The validation of the results will be effective only when the experimental results can be compared to simulation. However, as the methodology concerns predictive reliability, no return data are available. At this state, the best validation that can be done is to compare the results obtained by two different methods. 


\section{Case study application}

The objective of this study is to evaluate the predictive reliability of the PACK'AERO "Smart Actuator" using the proposed methodology. In addition to a conventional actuator, the smart actuator must provide additional functions such as control, monitoring, communication, information processing, etc. Thus, it should address several issues such as:

- Moving from passive system to active system (active vibration control, shock, etc.),

- Use of a direct linear action instead of indirect linear action (linear actuator),

- Optimization of an instantaneous response to meet the needs,

- Integration of electric locking functions with or without electric power consumption (magnet).

\subsection{External functional analysis}

\section{Context}

The smart actuator is a product that should be used in a chain of continuous sorting may include a number of trucks that can go from 200 to 1000 depending on the application (Fig. 6). The trucks transport parts from one station to another of the chain in continuous motion. The smart actuator contributes to the realization of the function of wagons unloading. The finger of the smart actuator is used as a stop to open the shutter and release (let go) the load of wagon without stopping.

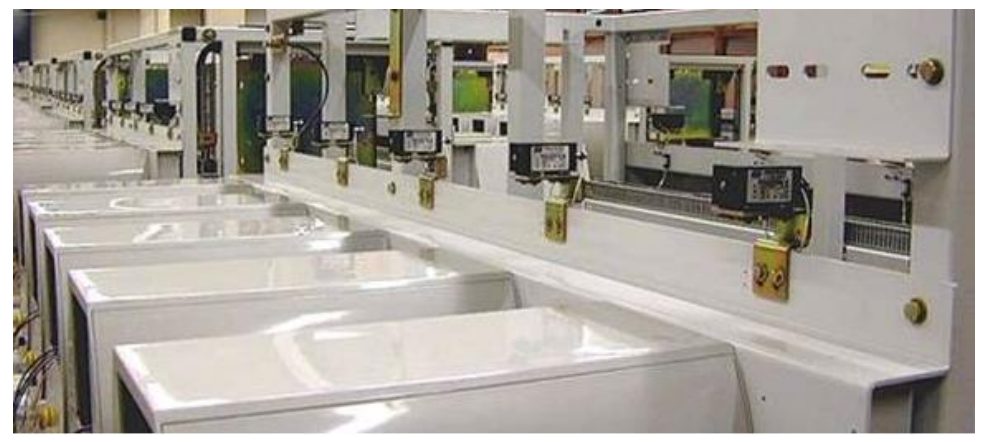

Fig. 6. Sorting chain

\section{Environment elements, main and constraint functions identification and description}

The octopus diagram of Fig. 7 presents the environment elements in relationship with the smart actuator as well as the main and constraint functions. Using this diagram, the analysis shows the presence of one main function (MF) and five constraint functions (CF) described as follows:

MF: Allows wagon shutter opening when the wagon arrives at the unloading station,

CF1: Withstands the thermal environment,

CF2: Works with the installed electrical power,

CF3: Meets the requirements of legislation,

$\mathrm{CF} 4$ : Meets the normative standards requirements,

CF5: Allows the master system to order operating (ON/OFF). 
G. Habchi and C. Barthod, An overall methodology for reliability prediction of mechatronic systems design with industrial application, Reliability Engineering \& System Safety, 155 (2016), 236-254, doi:10.1016/j.ress.2016.06.013

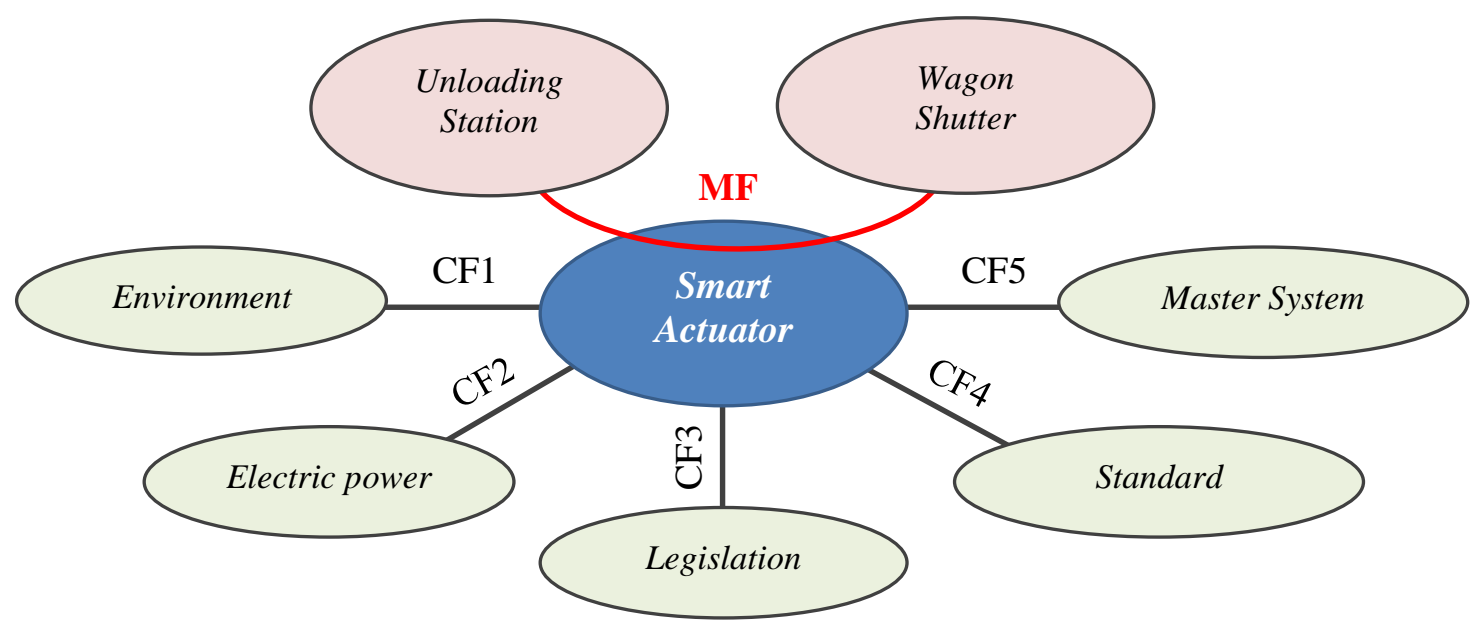

Fig. 7. Octopus diagram of the smart actuator

We present in Table 3, operating conditions, the characteristics of main function and constraints functions as well as some objectives related to reliability.

Table 4. Characteristics and objectives of the main function and constraint functions

\begin{tabular}{|c|c|c|}
\hline Function & Criteria/Target & Value/Information \\
\hline & $\begin{array}{l}\text { Average number of opening/closing cycles before } \\
\text { the occurrence of a first failure (MTTF) }\end{array}$ & 10 million of cycles \\
\hline & Desired lifetime & 10 years \\
\hline$M F$ & Operating information & $\begin{array}{l}\text { Intermittent operation } \\
\text { Electric power: } 1 \text { slot } \mathrm{ON}-\mathrm{OFF} / 60 \mathrm{~ms} \\
\text { Duration of an opening/closing cycle: } 40 \mathrm{~ms} \\
\text { Time between two cycles: } 1.67 \mathrm{~s} \\
\text { Operation time } 20 \mathrm{~h} / 24,6 \text { days } / 7\end{array}$ \\
\hline CF1 & $\begin{array}{l}\text { Temperature and duration of the hot phase } \\
\text { Temperature and duration of the cold phase } \\
\text { Temperature and duration of the temperate phase }\end{array}$ & $\begin{array}{l}120^{\circ} \mathrm{C} \text { for } 2 / 12 \text { of cycles } \\
5^{\circ} \mathrm{C} \text { for } 4 / 12 \text { of cycles } \\
70^{\circ} \mathrm{C} \text { for } 2 \text { times } 3 / 12 \text { of cycles }\end{array}$ \\
\hline CF2 & Electric power and voltage & $10 \mathrm{~W}$ and $24 \mathrm{~V}+/-5 \%$ \\
\hline CF3 & Meet the legislation requirements & $\begin{array}{l}\text { Low Voltage Directive: NSC 20-030 } \\
\text { Directive clean machine (Example: Noise } \\
\text { emitted by equipment NFEN 11201) }\end{array}$ \\
\hline CF4 & Meet the normative standard requirements & $\begin{array}{l}\text { Degree of electrical protection: NFEN60529 } \\
\text { Noise emitted by equipment: NFEN } 11201\end{array}$ \\
\hline CF5 & $\begin{array}{l}\text { Working order } \\
\text { Stop order }\end{array}$ & $\begin{array}{l}\text { TOR function (1) } \\
\text { TOR function (0) }\end{array}$ \\
\hline
\end{tabular}

\section{Mission profile}

The mission profile also called life profile determines the conditions of use of the product related to its environmental context. For the smart actuator, the yearly operating profile is defined by the main function and the constraint function CF1 (Table 3). The influence factor of the different phases of operation is the temperature, the level of thermal environment is organized as follows (Table 4):

3 operation months for "temperate" phase,

4 operation months for "cold" phase,

3 operation months for "temperate" phase,

2 operation months for "hot" phase. 
The used yearly mission profile is shown in Table 3 where operating durations are given in hours and number of cycles: the annual duration represents the total duration of each phase in hours for a year, the number of cycles represents the sum of cycles to be executed during each phase, operating time represents the time spent during the execution of cycles for each phase, and temperature column provides the value in Celsius degrees in which the smart actuator should operate. Is the number of cycles that will be used as usual duration for the quantification of reliability.

Table 5. Annual mission profile of the smart actuator

\begin{tabular}{lcccc}
\hline Phases & Annual duration $(\mathbf{h})$ & Number of cycles & Operating time (h) & Temperature $\left({ }^{\circ} \mathbf{C}\right)$ \\
\hline Temperate & 1565 & 3380400 & 38 & 70 \\
Cold & 2087 & 4507200 & 50 & 5 \\
Temperate & 1565 & 3380400 & 38 & 70 \\
Hot & 1043 & 2253600 & 25 & 120 \\
Stop & 2500 & 0 & 0 & 25 \\
\multicolumn{1}{r}{ Total } & 8760 & 13521600 & 151 & \\
\hline
\end{tabular}

\subsection{Internal functional analysis}

The internal functional analysis identifies the key internal functions that are necessary to achieve the main function (MF) of the smart actuator. Fig. 8 describes the bloc diagram of the functional architecture for the smart actuator in which we have identified 8 internal functions.

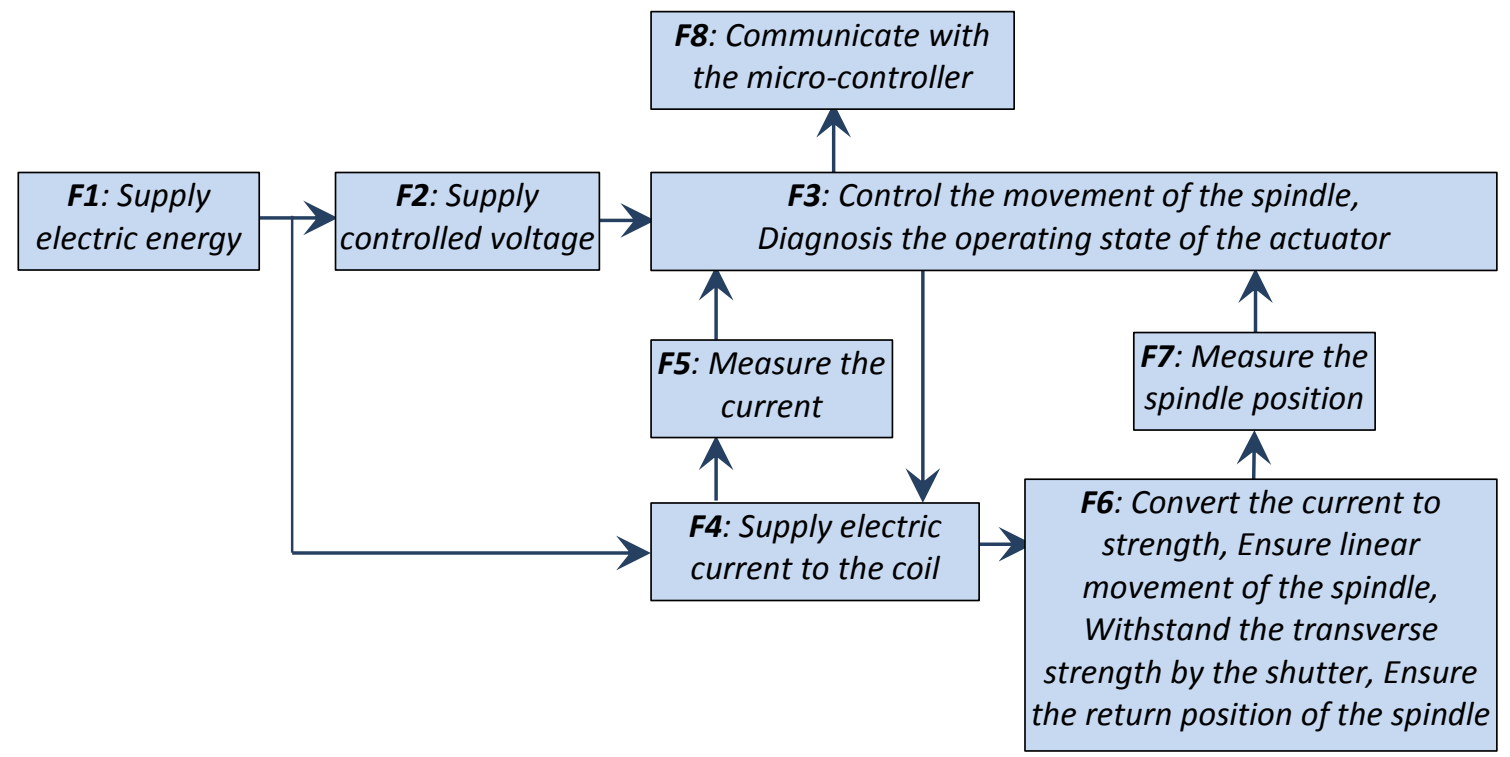

Fig. 8. Functional architecture bloc diagram of the smart actuator

\subsection{Organic analysis}

The purpose of the organic analysis is to define the architecture of the system, the decomposition into sub-systems and components and the interactions between the different elements of the system.

\section{Identification of components to be associated with internal functions}

Based on the internal functional analysis, it is therefore possible to identify the components that should carry out internal functions. The identified components are summarized in Table 5 for each function. 
G. Habchi and C. Barthod, An overall methodology for reliability prediction of mechatronic systems design with industrial application, Reliability Engineering \& System Safety, 155 (2016), 236-254, doi:10.1016/j.ress.2016.06.013

Table 6. Components associated with internal functions

\begin{tabular}{|c|c|c|}
\hline ID & Function description & Component \\
\hline$F 1$ & Supply electric energy & Power \\
\hline$F 2$ & Supply controlled voltage & Controlled power \\
\hline$F 3$ & 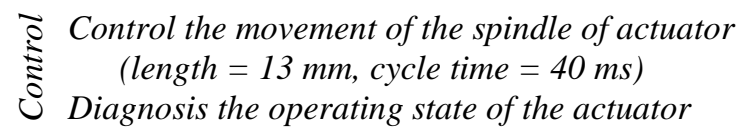 & Micro-controller $(H W \& S W)$ \\
\hline F4 & Measure the current (power) & Current (power) sensor \\
\hline$F 5$ & Supply electric current (power) to the coil & H-bridge \\
\hline F6 & $\begin{array}{l}\text { Convert the current to strength on the spindle } \\
\text { Ensure linear movement of the spindle }(13 \mathrm{~mm}) \\
\text { Ensure the end stops of the spindle } \\
\text { Support the transverse strength applied by the } \\
\text { shutter on the spindle } \\
\text { Ensure the return position of the spindle }\end{array}$ & $\begin{array}{l}\text { Moving coil } \\
\text { Fixed inductor with magnet } \\
\text { Tappet } \\
\text { Guide bearing } \\
\text { Return spring }\end{array}$ \\
\hline F7 & Measure the spindle position & $\begin{array}{l}\text { Conditioning circuit board for Hall sensor } \\
\text { Hall sensor } \\
\text { Magnet }\end{array}$ \\
\hline F8 & Communicate with the micro-controller & Master system \\
\hline
\end{tabular}

\section{Organic architecture of the smart actuator}

The decomposition of the smart actuator into sub-systems and components is described in Fig. 9.

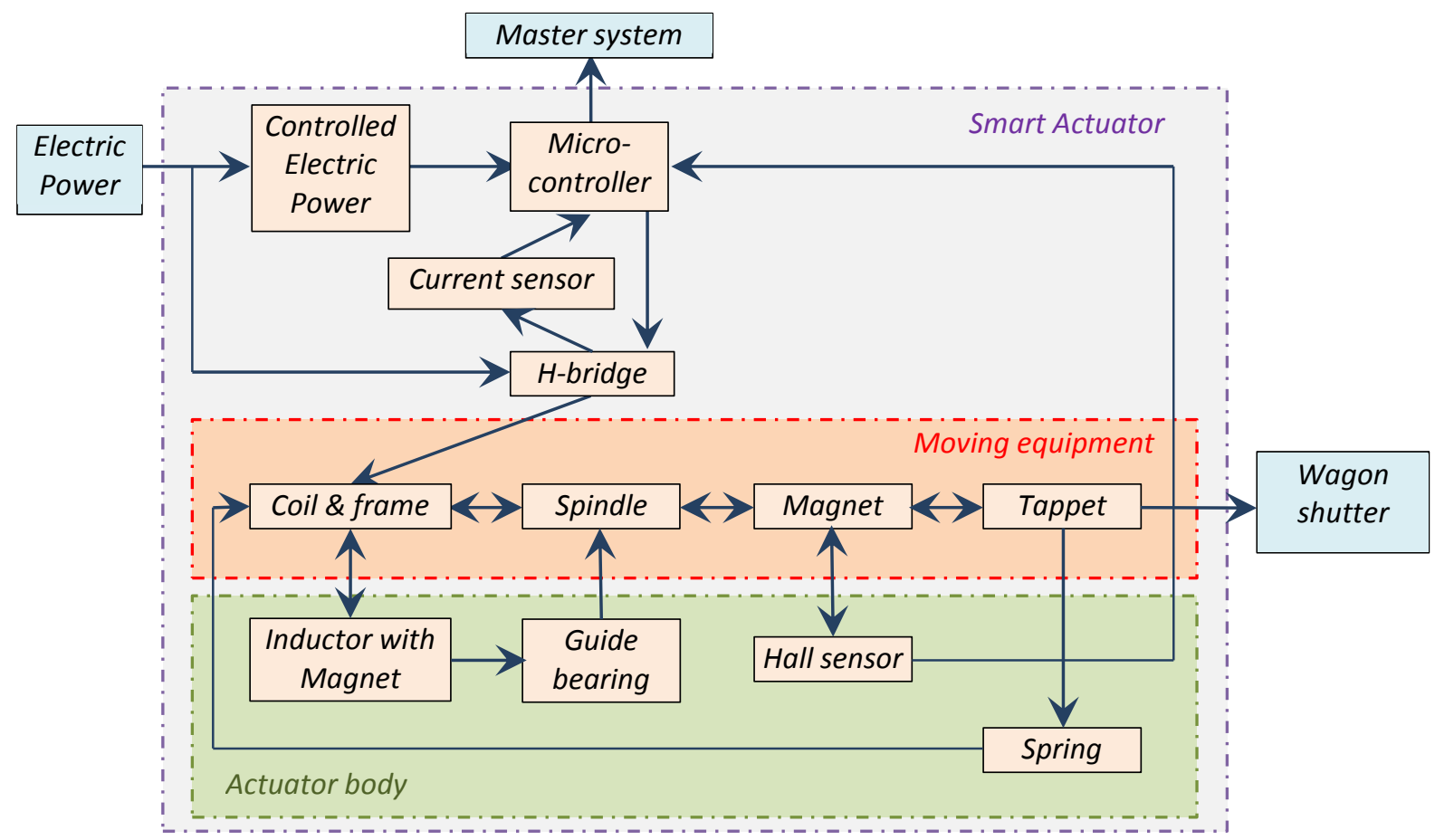

Fig. 9. Organic architecture of the smart actuator

Seven sub-systems could be identified:

- Electronic for control and self-diagnosis (controlled electric power, micro-controller, current sensor, H-bridge),

- Conditioning circuit board for Hall sensor,

- Actuator body (inductor with magnet, guide bearing, Hall sensor, spring),

- Moving equipment (coil \& frame, spindle, magnet, tappet), 
- Electrical connects (power supply/actuator body, power between the circuit board and the moving equipment),

- Mechanical support of the circuit board/actuator body,

- Mechanical fixation of the actuator body on the machine.

\subsection{Physical implementation}

The physical implementation aims to identify collateral damage among the different elements of the system to identify failures principally seconds, i.e., those which are caused by another adjacent component that is poorly designed, poorly machined or poorly defined.

Regarding electronics, a single double-sided printed circuit board should include both the control and diagnosis and the conditioning circuit board for Hall sensor. The design process predicts a control circuit board integrating 43 electronic components and a conditioning circuit board integrating 30 electronic components. This information is necessary to calculate the failure rate of electronic subassemblies.

\subsection{Dysfunctional analysis}

The organic architecture and the physical implementation of the smart actuator, allow identifying the functional damages that can affect the operation of the system. The physical location of the components, allows identifying collateral damage which causes failures of type "second". Intrinsic damages are damage-specific components i.e. that lead to failures of type "first".

\subsection{Dependability analysis (Interactions analysis)}

To study the dependability between the components of the smart actuator, we constructed a component by component matrix based on the organic architecture, the physical implementation and the dysfunctional analysis as it is expected by the overall methodology. However, in order to not overload the paper, the matrix is presented as a list of possible unidirectional and bidirectional interactions:

- Power supply acts on controlled power and on H-bridge,

- Controlled power acts on micro-controller,

- H-bridge acts on current sensor and on coil,

- Micro-controller acts on H-bridge and on master system,

- Current sensor acts on micro-controller,

- Coil acts on shutter,

- Magnet acts on tappet and on Hall sensor,

- Coil acts on inductor \& magnet / inductor \& magnet acts on coil,

- Magnet acts on shutter/Shutter acts on magnet.

\subsection{Qualitative modeling}

The objective of the qualitative analysis is to model the functional and dysfunctional behaviors of the smart actuator. The models are based on all the steps upstream developed.

The FMEA study supplemented by the classification of failure modes of the components according to their nature (first or second), their establishment speed (sudden, progressive) and their amplitude (partial or complete) requires introducing failure modes and additional states. Indeed, failure modes commonly used in modeling are first failure modes. To take into account the interactions inducing collateral damage, the second failure modes are added.

Similarly, the states: "operation", "breakdown", "idle" and "repair" should be enriched with the state "degraded" which takes into account the magnitude of the failure. A "degraded" condition is defined as a condition in which the characteristics of the element are altered: the element remains functional but admits lower performance. 
G. Habchi and C. Barthod, An overall methodology for reliability prediction of mechatronic systems design with industrial application, Reliability Engineering \& System Safety, 155 (2016), 236-254, doi:10.1016/j.ress.2016.06.013

The figures (Fig. 10, Fig. 11, and Fig. 12) have a qualitative modeling of single step, of the single coil and the two elements with consideration of the interaction between the two. The states considered for the different elements are then:

- Actuator states: idle, operating, breakdown (whatever the mission profile phase), repair and degraded,

- Sub-system states: idle, operating, breakdown (depending on the phase "tempered", "cold" or "hot"), repair and degraded.

Fig. 10 shows the functional and dysfunctional model of the guide bearing considered alone.

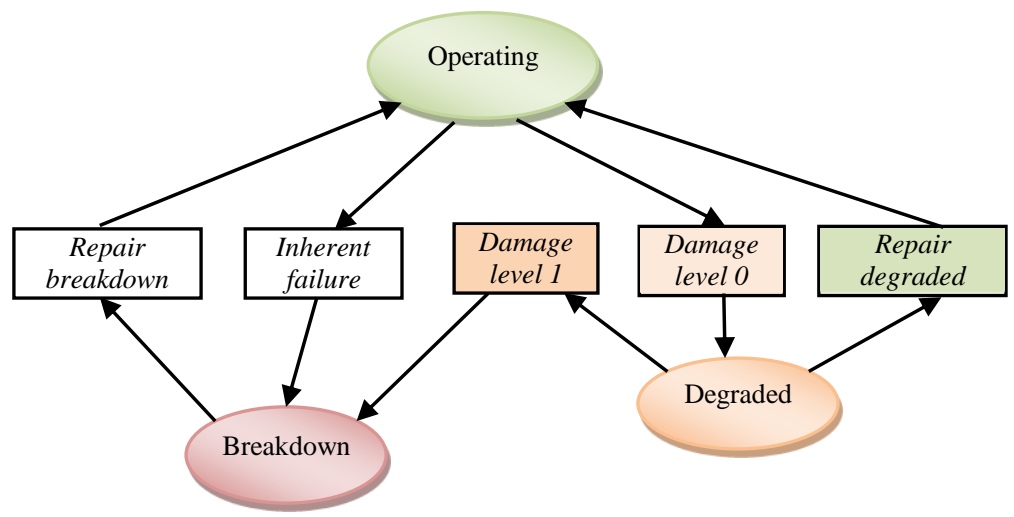

Fig. 10. Functional and dysfunctional model of the guide bearing.

Fig. 11 shows the functional and dysfunctional model of the coil considered alone.

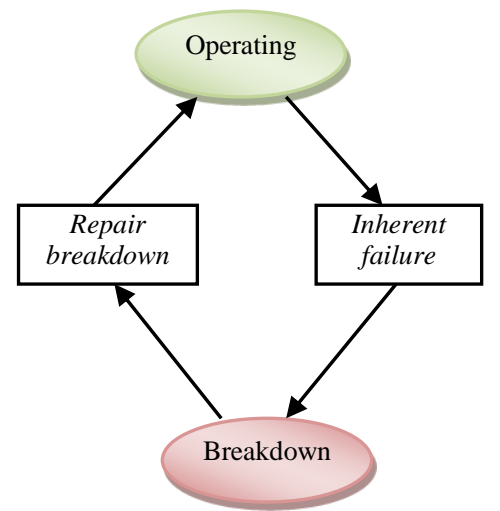

Fig. 11. Functional and dysfunctional model of the coil.

Fig. 12 shows the qualitative model of the bearing and coil taking into account the unidirectional interaction bearing/coil. 


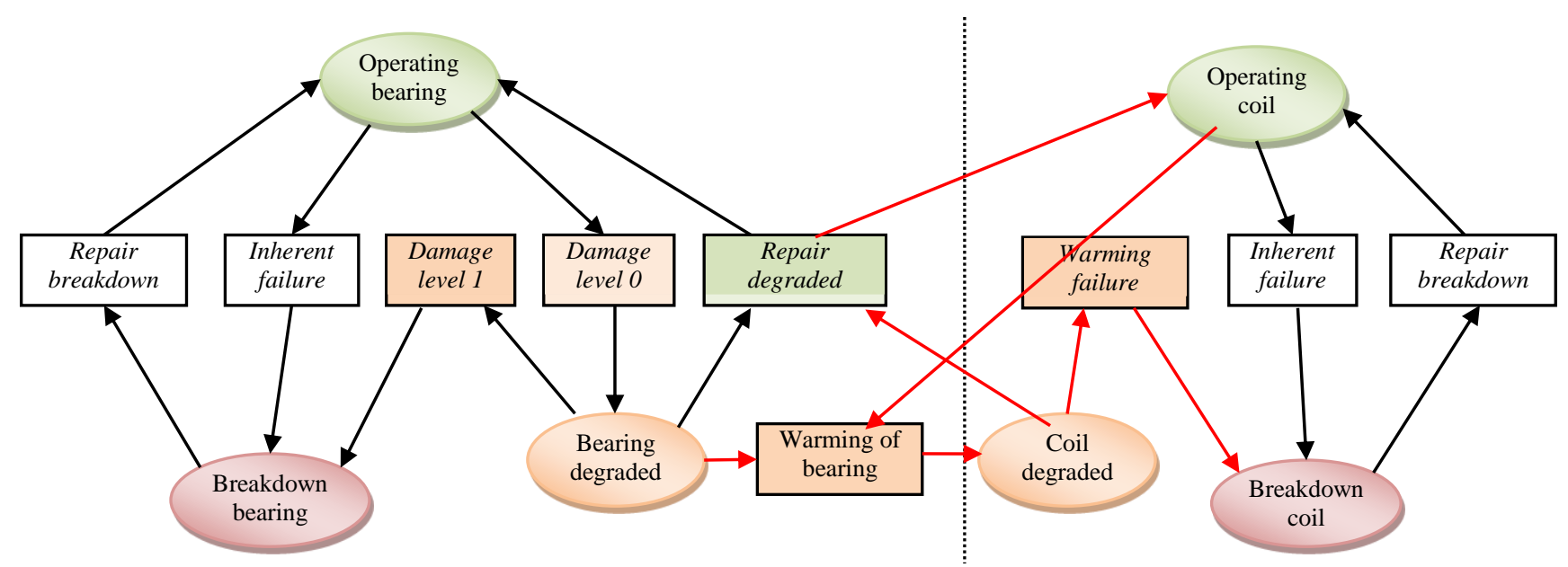

Fig. 12. Functional and dysfunctional model of the bearing and coil considered together.

\subsection{Data gathering and processing}

This step is to make a wise choice of reliability distributions and parameters associated with each component to achieve the modeling steps and dynamic simulation. Table 6 presents the reliability distributions and parameters for each component of the actuator according to its technology. It should be noted that during the phases "cold" and "temperate" of the mission profile, the value of parameters is constant while during the "hot" phase the value of parameters evolves according to linear laws for both interaction levels.

For components having mechanical technology, this is the two-parameter Weibull distribution which was chosen while for electrical and electronic components or subsystems, we considered the exponential distribution.

With respect to the phases of the mission profile, the different values of the "mean time between failures" and the "failure rate" of the electronic components and/or sub-systems have been obtained using FIDES approach and EasyRel software.

For mechanical components, the values of the parameters of the Weibull distribution and their evolution are issued from the industrial know-how.

Table 7. Values of distribution parameters for the components and/or subsystems

\begin{tabular}{|l|l|l|c|c|c|}
\cline { 4 - 5 } \multicolumn{2}{c|}{} & \multicolumn{3}{c|}{$\begin{array}{c}\text { Parameters value during profile mission phases } \\
\text { (Millions of cycles for MTBF and } \eta \text { ) }\end{array}$} \\
\hline Distribution & $\begin{array}{l}\text { Component/ } \\
\text { Subsystem }\end{array}$ & Failure Mode & Cold & $\begin{array}{c}\text { Temperat } \\
\text { e }\end{array}$ & Hot \\
\hline $\begin{array}{l}\text { Weibull } \\
(\beta-\eta)\end{array}$ & Bearing & $\begin{array}{l}\text { Intrinsic } \\
\text { Level0 Damage } \\
\text { Levell Damage }\end{array}$ & $\begin{array}{c}\beta: 2 \\
\eta: 92000\end{array}$ & $\begin{array}{c}\beta: 2,5 \\
\eta: 1000\end{array}$ & $\begin{array}{c}\beta: 1,5-\eta: 31,24 \\
\eta: 31,24 \rightarrow 29,68 \\
\eta: 29,68 \rightarrow 23,43\end{array}$ \\
\hline \multirow{5}{*}{$\begin{array}{l}\text { Exponential } \\
(\text { MTBF })\end{array}$} & Coil & $\begin{array}{l}\text { Intrinsic } \\
\text { Level0 Interaction } \\
\text { Levell Interaction }\end{array}$ & 122358 & 1352 & $\begin{array}{c}42,373 \rightarrow 40,254 \\
40,254 \rightarrow 31,78\end{array}$ \\
\cline { 2 - 6 } & Control & Intrinsic & 3916179 & 197685 & 1858 \\
\cline { 2 - 6 } & Conditioning & Intrinsic & 8835645 & 215917 & 12544 \\
\cline { 2 - 6 } & Magnet Inductor & Intrinsic & 122358 & 1326 & 42,27 \\
\cline { 2 - 6 } & Sensor & Intrinsic & 17824 & 17824 & 17824 \\
\hline
\end{tabular}

Fig. 13 shows the evolution of the eta parameter of the Weibull distribution for the bearing depending on the mission profile. Because of the very low values of the parameter eta during the "hot" phase, the vertical scale has been transformed into logarithmic. Eta values are in millions of cycles. If the 
G. Habchi and C. Barthod, An overall methodology for reliability prediction of mechatronic systems design with industrial application, Reliability Engineering \& System Safety, 155 (2016), 236-254, doi:10.1016/j.ress.2016.06.013

interaction between the bearing and coil is taken into account during the hot phase of the mission profile, the values of eta diminish linearly into two periods corresponding to the two states of degradation of the bearing: level0 and levell damage.

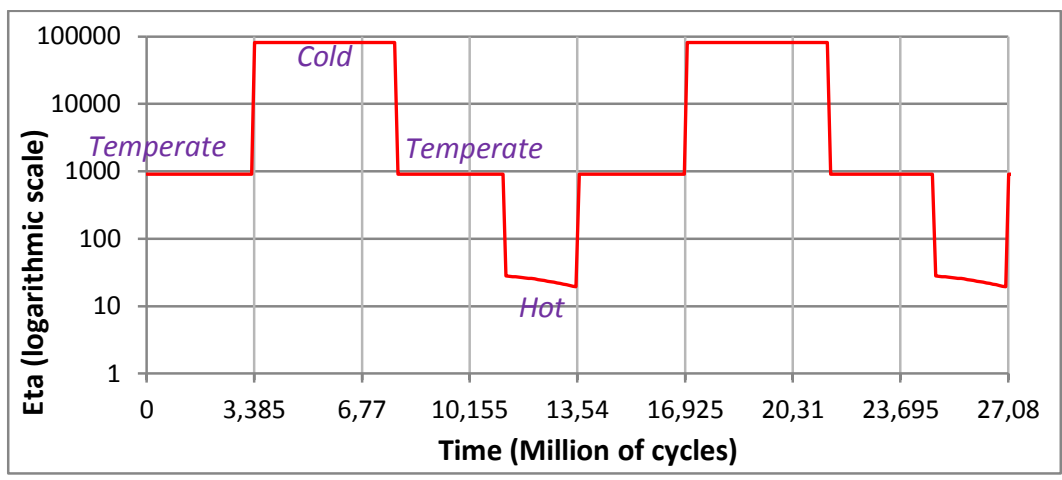

Fig. 13. Evolution of Weibull Eta parameter for the bearing according to the mission profile

Also, Fig. 14 shows the evolution of the MTBF parameter of the exponential distribution for the coil depending on the mission profile. For the same reasons, the vertical scale has been transformed into logarithmic one. MTBF values are in millions of cycles. Likewise, during the hot phase, the values of MTBF diminish linearly into two periods corresponding to the two states of interaction of the coil with the bearing: level0 and level1 interaction.

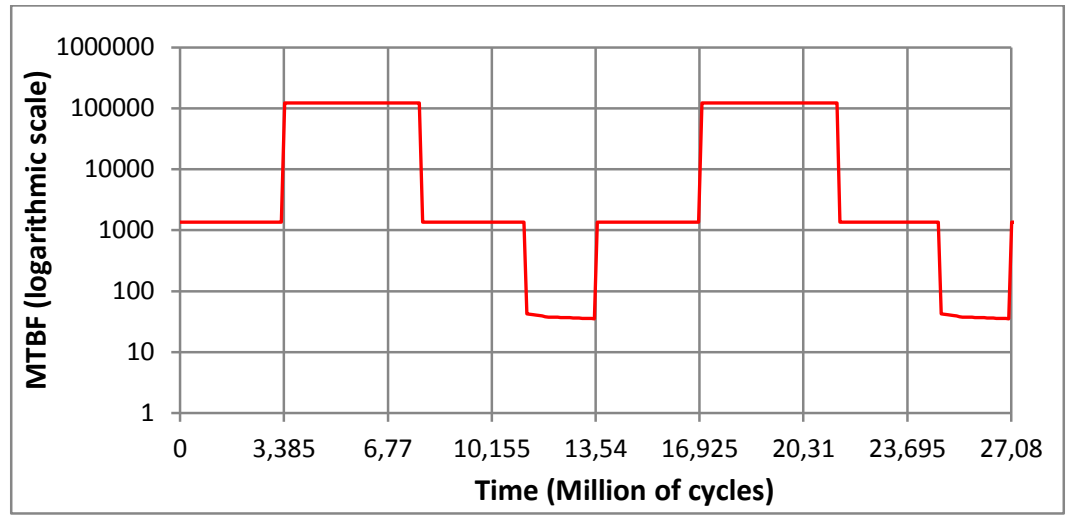

Fig. 14. Evolution of Exponential distribution mean for the coil according to the mission profile

\subsection{Modeling and simulation}

\section{Modeling approaches}

As discussed previously, two modeling approaches are used to implement the reliability calculation of the smart actuator and its components: Petri Nets \& Monte-Carlo simulation, and Reliability Block Diagrams. The comparison of the results achieved by the two approaches is necessary to verify and validate models for both methods. Two tools were used: MOCA-RP for Petri Nets modeling and ADONIS for reliability block diagrams calculation.

Fig. 15 and Fig. 16 show by way of example the PN models of the coil and the smart actuator. For the coil, the model shows the detail needed on all phases of the mission profile taking into account both the ability to interact or not with the bearing guide. 
G. Habchi and C. Barthod, An overall methodology for reliability prediction of mechatronic systems design with industrial application, Reliability Engineering \& System Safety, 155 (2016), 236-254, doi:10.1016/j.ress.2016.06.013

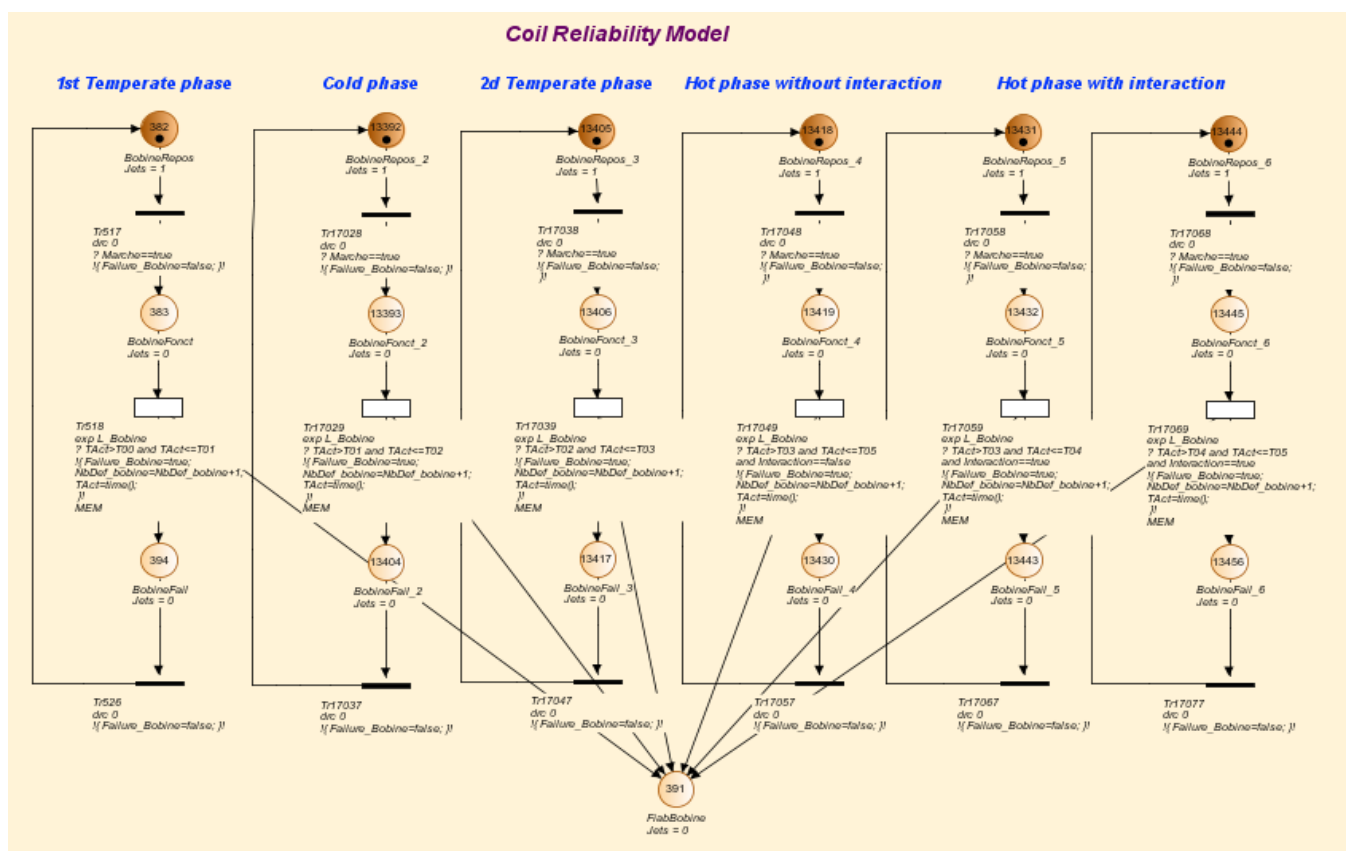

Fig. 15. Petri net model of the coil component considering profile mission and interaction modeling

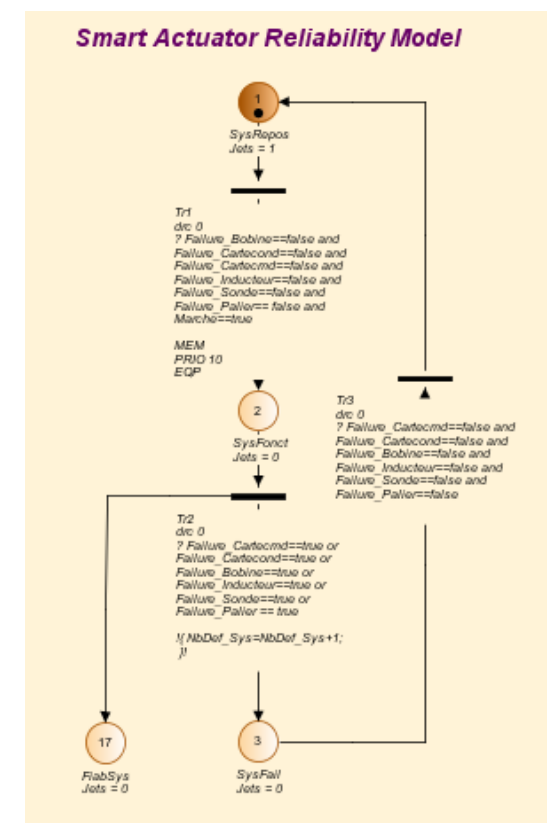

Fig. 16. Petri net model of the smart actuator

On the other side, Fig. 17 shows the reliability block diagram of the smart actuator. It is a series diagram of six components/sub-systems considered in modeling. By way of example, Fig. 18 and Fig. 19 show for the guide bearing, the information entered for the Weibull distribution and the different phases of the mission profile.

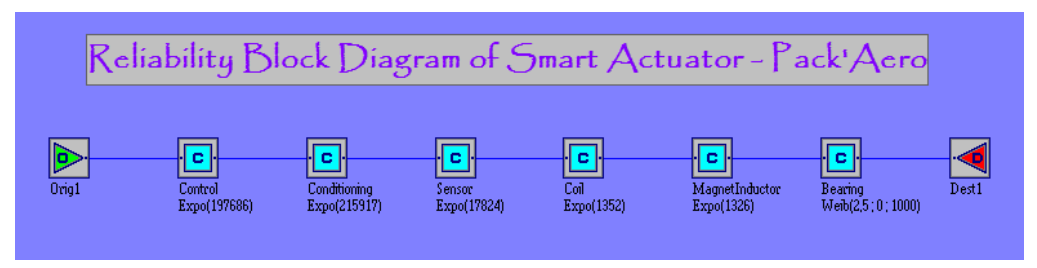

Fig. 17. Reliability Block Diagram series model of the smart actuator 


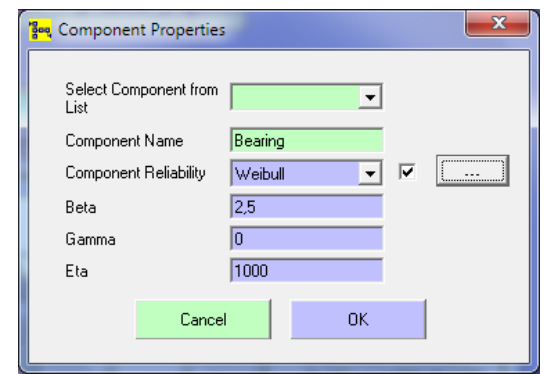

Fig. 18. Weibull distribution for bearing component with initial values of parameters

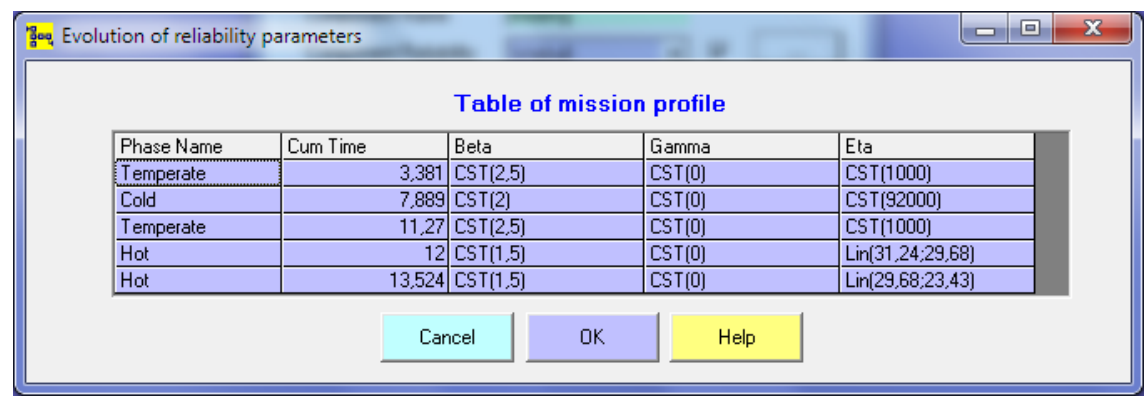

Fig. 19. Bearing mission profile phases considering interaction during the last two hot phases

\section{Monte-Carlo simulation and calculation using reliability block diagrams assumptions}

Regarding the assessment of the reliability by simulation, the dynamics of Petri Net model is simulated for 10 years (about 135 millions of cycles) in steps of approximately 0,5634 millions of cycles to get 240 points corresponding to 120 months ( 2 points per month). At each step, the transition conditions are checked and the failure time values are based on a random number. The change of state occurs when the conditions associated with the transitions are true. The 10 years simulation cycle of the PN model is repeated a sufficient number of times (300,000 times) so that the average results converge (Monte Carlo simulation).

In order to compare the results, we used the same assumptions for computing reliability using reliability block diagrams, i.e., the calculation step and the duration of ten years.

\subsection{Results analysis}

\section{Reliability analysis, phase by phase without interaction}

The reliability results issued from the execution of the two approaches are presented graphically in Fig. 20 to Fig. 26. For all of these graphs, the horizontal axis represents the time in millions of cycles and the vertical axis the reliability (value between 0 and 1 ).

First, the three Figs. 20 to 22 have the reliability of the smart actuator and its components independently, during the three phases of the mission profile: "cold", "temperate" and "hot". These graphs are obtained both by simulation of the PN model and the reliability block diagram, assuming no interaction between components.

From Fig. 20, we can perceive that if the smart actuator operated continuously according to "cold" phase, its reliability remains of the order of 0.99 after 10 years of operation. Indeed, some of its components keep reliability of the order of 1. Likewise, as shown in Fig. 21, the reliability of the smart actuator reached 0.8 after 10 years of continuous operation, depending on the phase "temperate". This interprets into about $20 \%$ of failed products during this period. Whereas, as shown in Fig. 22 the lifetime of the smart actuator hardly reaches 5 years (67.7 million cycles), if it operated continuously along the "hot" profile. Indeed, the reliability of the smart actuator falls sharply during the first two years to about 0.1 . Whatever the considered phase of the mission profile, the least reliable components are the guide bearing and the magnet inductor. 
G. Habchi and C. Barthod, An overall methodology for reliability prediction of mechatronic systems design with industrial application, Reliability Engineering \& System Safety, 155 (2016), 236-254, doi:10.1016/j.ress.2016.06.013

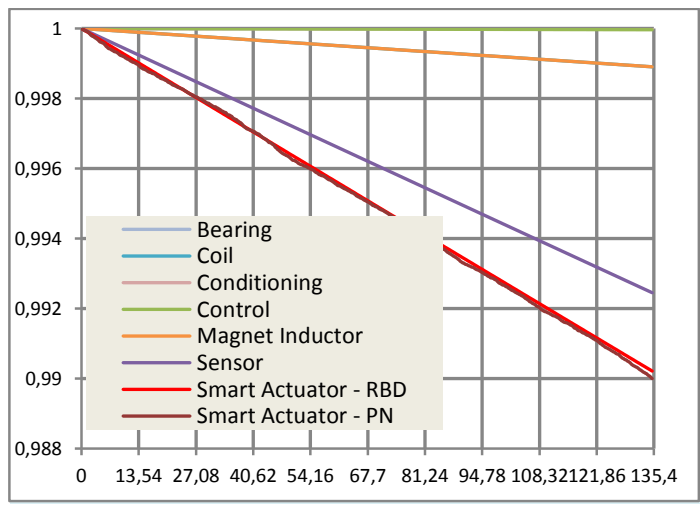

Fig. 20. Reliability of the smart actuator and its components during the "cold" phase

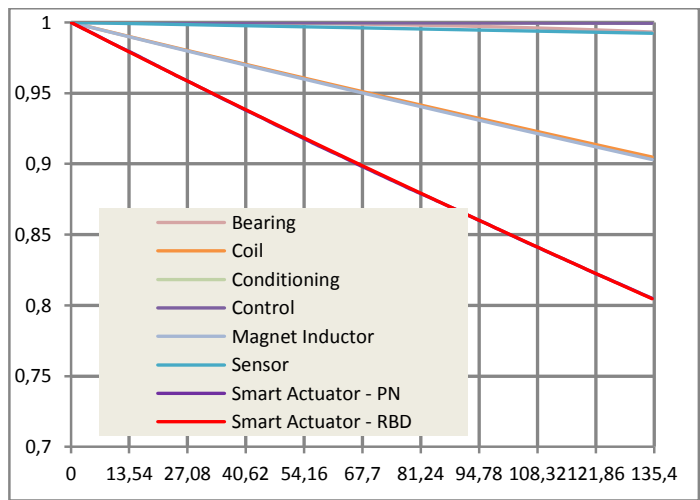

Fig. 21. Reliability of the smart actuator and its components during the "temperate" phase

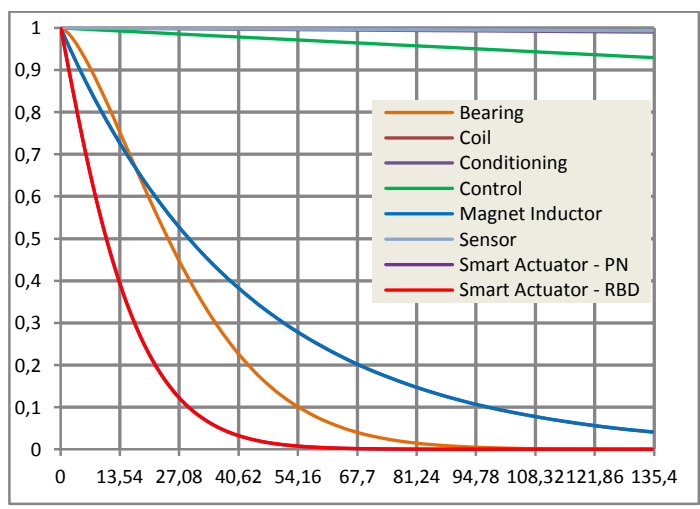

Fig. 22. Reliability of the smart actuator and its components during the "hot" phase

Fig. 23 shows the reliability of the smart actuator during the three phases of the mission profile independently considered, assuming no interaction between components. The temperature appears to be a very influential factor on the reliability of the considered system. The more the temperature rises less its lifetime is long. Actually, after 5 years of operation (67.7 million cycles): according to the "cold" phase $99 \%$ of the products are reliable, depending on the phase "temperate" $90 \%$ are still alive, and according to the "hot" phase $100 \%$ of products are not in use. 
G. Habchi and C. Barthod, An overall methodology for reliability prediction of mechatronic systems design with industrial application, Reliability Engineering \& System Safety, 155 (2016), 236-254, doi:10.1016/j.ress.2016.06.013

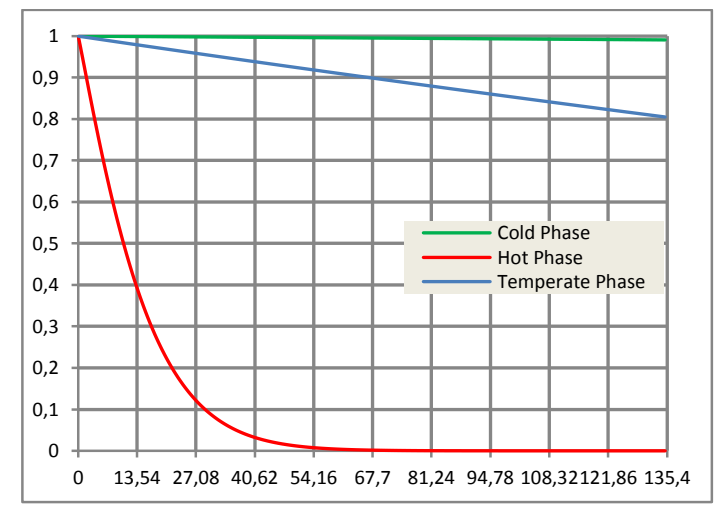

Fig. 23. Reliability of the smart actuator during the three phases of the mission profile

\section{Reliability analysis, with consideration of the interaction}

In this part, we consider the interaction bearing guide / coil during the "hot" phase of the mission profile. We notice on Fig. 24 that after a 6 million operating cycles, the reliability of the two components in question drops sharply to zero after about 14 million cycles. The reliability of the smart actuator is also zero after only one year of operation.

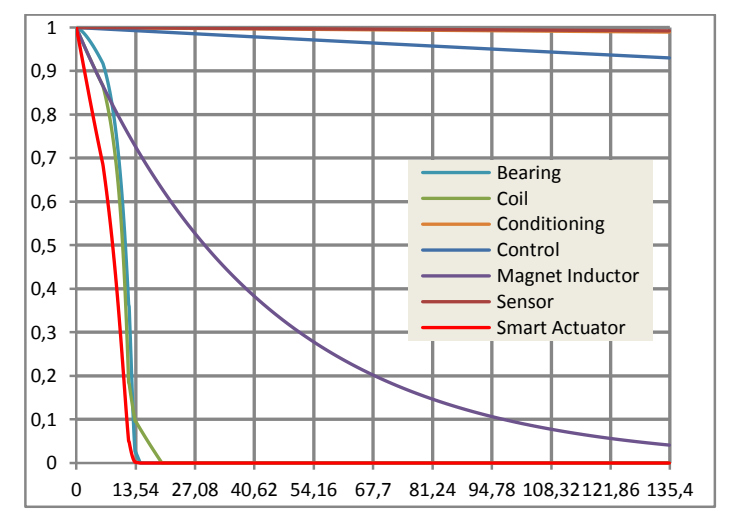

Fig. 24. Reliability of the smart actuator and its components during the "hot" phase with consideration of the bearing/coil interaction

Fig. 25 shows the reliability of the smart actuator for the "hot" phase without and with consideration of the interaction. It is important to emphasize that the effect of the interaction is significant on system failure, and it can be concluded that it is absolutely necessary to consider dependencies between components in a complex system because reliability is greatly influenced.

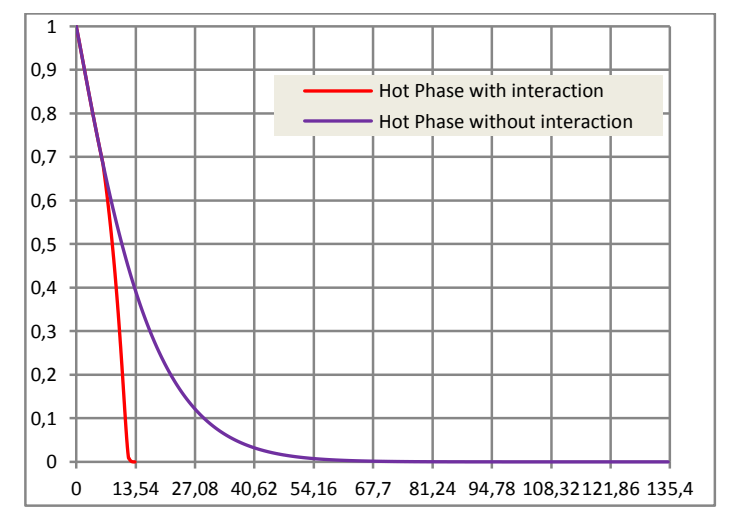

Fig. 25. Reliability of the smart actuator during the "hot" phase without and with consideration of the interaction 


\section{Reliability analysis according to the mission profile}

Fig. 26 (left) shows in both cases, with and without consideration of the interaction bearing guide / coil, the reliability of the smart actuator for 10 years, according to the mission profile. Reliability decreases by corresponding bearings in successive hander at different phases of mission profile. It is easy to notice on the right graph of Fig. 26, the succession of phases in the following order: "temperate", "cold", "temperate", "hot". Indeed, the slope of the reliability curve depends on the considered phase, so that the temperature surrounding the system during operation. This slope is almost flat in the "cold" phase and very abrupt in the "hot" phase. Also, we can notice that during the "cold" and "tempered" phases the slope does not change whatever the case with or without interaction, whereas the slope is stronger with interaction during the "hot" phase compared to the case without interaction.
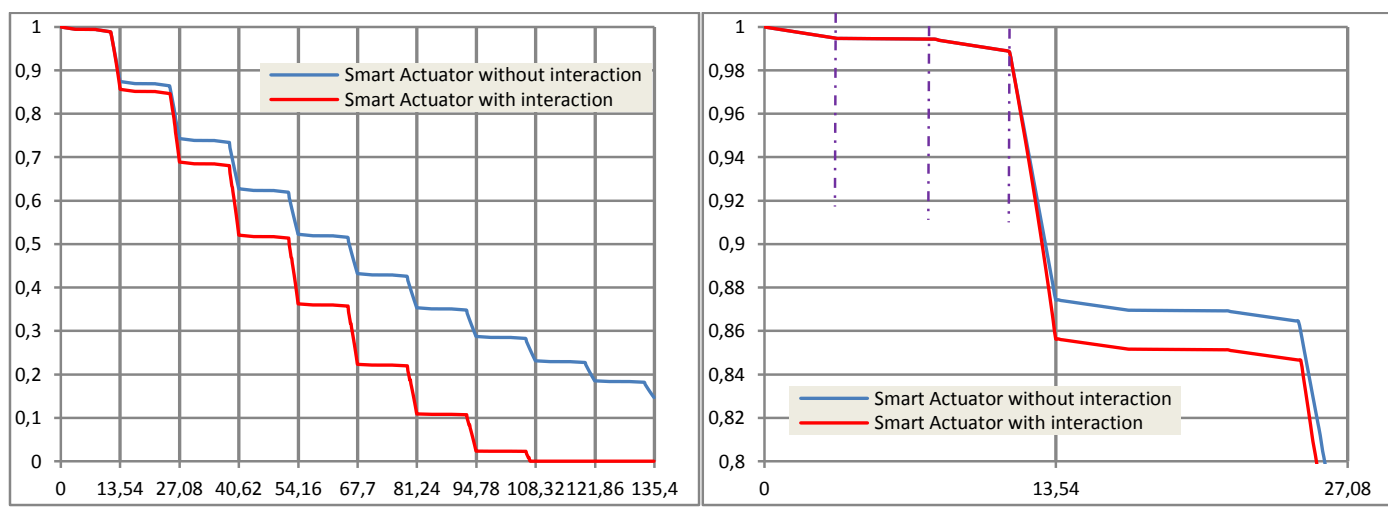

Fig. 26. Reliability of the smart actuator during mission profile phases without and with consideration of the bearing/coil interaction

Finally, we can observe the effect of the interaction taking into consideration in modeling the reliability of the system. Without consideration of interaction, about $15 \%$ of products can achieve a lifetime of 10 years, while considering the interaction bearing guide / coil, no product reached a lifetime of eight years.

\section{Conclusion}

In this article, we analyzed some of the problems associated with the reliability of mechatronic systems and we proposed an overall detailed ten-step methodology evaluating the predictive reliability that takes into account the specificities of these systems.

To evaluate the overall predictive reliability of a mechatronic system, it is necessary to have a model because the system doesn't exist at this stage of the development and cannot be physically tested. That is why the first part of the proposed methodology is a qualitative analysis that provides all the necessary information on the functioning and malfunctioning of a mechatronic system. The second part of the methodology is a quantitative analysis to estimate and quantify the reliability of the mechatronic system taking into account its specific conditions of use.

This ten-step approach allows formalizing the consideration of reliability at each step of the system design. The use of an enriched FMEA allows to identify the failure modes of the components and to classify them according to their nature (first or second), their establishment speed (sudden, progressive) and their amplitude (partial or complete). Following the proposed approach, the FMEA must rely on the dysfunctional analysis to select the functional failure modes. The collateral interactions may be determined by analyzing the physical implementation of the components. Thus, introducing new failure modes and additional states, a behavioral model can be built taking into account the mission profile (with different conditions of use), the progressive wear of components (if necessary), and the collateral and functional interactions.

The functional and dysfunctional behavior can be modeled thanks to data gathering and processing and by using either Petri Nets, or reliability block diagrams. 
We validated this methodology through industrial mechatronic examples. These examples are selected in collaboration with our partner CETIM which has very special relations with many companies working in the field of mechatronics. Also, we deepened our analysis on more theoretical questions, to respond in particular to the problems of specification and modeling, collateral and functional interactions in terms of reliability and the influence of the mission profile on the distribution laws for component reliability. Although the presented study considered only one environmental parameter (temperature), the approach allows taking into account simultaneously the influence of several factors as vibration, humidity... The main limit of the methodology is, once more, the lack of reliability data, in particular concerning mechanical pieces where no database exists. Moreover, to be able to take into account progressive damaging and collateral interaction, behavior laws in specific conditions of use for components are required. But, gathering such data are time and money consuming.

Compared with the literature review synthesized in Table 1, this methodology responds positively to all the addressed items with the exception of "human reliability analysis" and to a lesser extent "transverse dimension".

\section{Acknowledgements}

We would like to thank the APS (Assemblée des Pays de Savoie) and the CETIM (Centre Technique des Industries Mécaniques) who funded and supported this research. We would also like to thank Pack'Aero who has agreed to apply the approach on a mechatronic product developed by the company.

\section{References}

Alciatore D.G. and Histand M.B., Introduction to Mechatronics and Measurement Systems, Fourth Edition (2012), Mc Graw Hill, Publisher website: www.mhhe.com/alciatore.

Ashley, S. Getting a hold on mechatronics. Mechanical Engineering, (1997).

Belhadaoui H. Conception sûre des systèmes mécatroniques intelligents pour des applications critiques. Automatique. PhD Thesis, Institut National Polytechnique de Lorraine - INPL, (2011).

Belhadaoui Hicham. Conception sûre des systèmes mécatroniques intelligents pour des applications critiques. Automatique. PhD Thesis, Institut National Polytechnique de Lorraine - INPL, (2011).

Bertram T., Bekes F., Greul R., Hanke O., Hab C., Hilgert J., Hiller M., Ottgen O., Opgen-Rhein P., Torlo M., Ward D. Modelling and simulation for mechatronic design in automotive systems. Control Engineering Practice, 11 (2003) 179-190.

Bertrand de la Bretesche, La méthode APTE: Analyse de la valeur, analyse fonctionnelle, Pétrelle, (2000) (ISBN 978-2-84440-019-2)

Cai B., Y. Liu, Y. Ma, Z. Liu, Y. Zhou, J. Sun. Real-time reliability evaluation methodology based on dynamic Bayesian networks: A case study of a subsea pipe ram BOP system, ISA Transactions, 58 (2015) 595-604.

CEI 50 191, 1990, International Electro-Technical Vocabulary, Chapter 191: Dependability and quality of service. CEI, (1990).

CETIM, Guide de conduite d'un projet mécatronique. Analyse fonctionnelle et organique, CETIM (2007).

Charki, A., Demri, A., Guerin, F. \& Bigaud, D. Mechatronic system reliability evaluation using Petri networks and phi2 method. Proc. ESREL'2009, Prague, Czech Republic, 7-10 September (2009).

Daniel O. Les réseaux de petri stochastiques pour l'évaluation des attributs de la sûreté de fonctionnement des systèmes manufacturiers. PhD thesis, LAG Grenoble, (1995).

Daniel R.W., Hewit J.R. Editorial. Mechatronics, 1(1) (1991) i-ii.

David R. et H. Alla. Du Grafcet aux réseaux de Petri. Hermes, (1992).

Demmou H., S. Khalfaoui, E. Guilhem, R. Valette: Critical scenarios derivation methodology for mechatronic systems, Reliability Engineering and System Safety, 84 (2004) 33-44.

Demri A. Contribution à l'évaluation de la fiabilité d'un système mécatronique par modélisation fonctionnelle et dysfonctionnelle. PhD thesis, Université d'Angers, (2009).

DesJardin L. A day in the life of mechatronic engineers 10 years from now. In SAE International Congress and Exposition, number SAE96C038, Detroit/Michigan, USA, (1996).

Distefano Salvatore, Antonio Puliafito, Dependability Evaluation with Dynamic Reliability Block Diagrams and Dynamic Fault Trees. IEEE Trans. Dependable Sec. Comput. 6(1) (2009) 4-17.

Doyle, R. Mechanical reliability. In RAMS Tutorial Notes, USA, (1991). 
G. Habchi and C. Barthod, An overall methodology for reliability prediction of mechatronic systems design with industrial application, Reliability Engineering \& System Safety, 155 (2016), 236-254, doi:10.1016/j.ress.2016.06.013

Droguett E., R. Menêzes. Human analysis through Bayesian networks: an application in maintenance of transmission lines. Production, 17 (1) (2007) 162-85, http://dx.doi.org/10.1590/S0103-65132007000100012.

Dutuit Y., E. Châtelet, J.-P. Signoret et P. Thomas. Dependability modeling and evaluation by using stochastic Petri nets: Application to two test cases. Reliability Engineering \& System Safety, 55 (2) (1997) 117-124.

FIDES. Méthodologie de fiabilité pour les systèmes électroniques. (2009).

Foulliaron J., L. Bouillaut, A. Barros, P. Aknin. Dynamic bayesian networks for reliability analysis: from a Markovian point of view to semi-markovian approaches, IFAC-PapersOnLine 48-21 (2015) 694-700.

Goševa-Popstojanova Katerina, Kishor S. Trivedi, Architecture-based approach to reliability assessment of software systems, Performance Evaluation 45 (2001) 179-204.

Grimheden M., Hanson M. What is mechatronics proposing a didactical approach to mechatronics? In 1st Baltic Sea Workshop on Education in Mechatronics, Kiel, Germany, (2001).

Guenzi Giancarlo, Reliability evaluation of common-cause failures and other interdependencies in large reconfigurable networks. Dissertation submitted to the Faculty of the Graduate School of the University of Maryland, College Park, in partial fulfillment of the requirements for the degree of Doctor of Philosophy, (2010).

Guerin, F., Dumon, B., and Usureau, E. Reliability estimation by Bayesian method: Definition of prior distribution using dependability study. Reliability Engineering \& System Safety, 82(3) (2003) 299-306.

Hewit J. Mechatronics design - the key to performance enhancement. Robotics and Autonomous Systems, 19 (1996) 135-142.

Isermann R. Mechatronic systems - innovative products with embedded control. Control Engineering Practice, 10 (2007) 16.

Kayani, S.A. On automated design of mechatronic systems through bond-graphs and genetic programming. IEEE Multidisciplinary Engineering Education Magazine, 2(4) December (2007) 15-17.

Khalfaoui S. Méthode de recherche des scenarios redoutés pour l'évaluation de la sûreté de fonctionnement des systèmes mécatroniques du monde automobile. PhD thesis, Institut National Polytechnique, Toulouse, (2003).

Leondes C.T. Mechatronic Systems, Techniques and Applications. Vol. 5, Diagnostic, Reliability and Control System Techniques. Edited by C.T. Leondes, Gordon and Breach Science Publishers, (2000).

Li Z., Y. Deng, C. Mastrangelo. Model selection for degradation-based Bayesian reliability analysis. Journal of Manufacturing Systems, 37 (2015) 72-82.

Lin J., J. Pulido, M. Asplund. Reliability analysis for preventive maintenance based on classical and Bayesian semi-parametric degradation approaches using locomotive wheel-sets as a case study. Reliability Engineering and SystemSafety, 134 (2015) 143-156.

Liu Z., Y. Liu, B. Cai, D. Zhang, C. Zheng. Dynamic Bayesian network modeling of reliability of subsea blowout preventer stack in presence of common cause failures. Journal of Loss Prevention in the Process Industries, 38 (2015) 58-66.

Lyonnet P. Fiabilité Technique et Humaine, Lavoisier, (2012).

Marsan M. Ajmone, G. Balbo, G. Conte, S. Donatelli, G. Franceschinis, Modelling with Generalized Stochastic Petri Nets. Wiley Series in Parallel Computing, John Wiley and Sons, (1994), ISBN: 0-471-93059-8.

Martins M. Ramos, M. Coelho Maturana. Application of Bayesian Belief networks to the human reliability analysis of an oil tanker operation focusing on collision accidents. Reliability Engineering and System Safety, 110 (2013) 89-109.

Medjoudj M. Contribution à l'analyse des systèmes pilotés par calculateurs : Extraction de scenarios redoutés et vérification de contraintes temporelles. PhD thesis, Université Paul Sabatier, Toulouse, (2006).

Mihalache A. Modeling and evaluation of the reliability of mechatronic systems: application on embedded system. PhD thesis, University of Angers, (2007).

Mihalache, A., Bacivarov, I., Todoskoff, A., Barreau, M., Guerin, F., et Morel, J.-Y. Reliability evaluation of a complex mechatronic system: antilock brake system (abs). Assurance Qualité, VIII (32). Bucarest, Romania, (2002).

MIL-HDBK-338B. Military handbook electronic reliability design handbook, (1998).

Millbank J. Mecha-what! Mechatronics Forum Newsletter, 6 (1993).

Mkrtchyan L, L. Podofillini, V.N. Dang. Bayesian belief networks for human reliability analysis: A review of applications and gaps. Reliability Engineering and System Safety, 139 (2015) 1-16.

Mkrtchyan L, L. Podofillini, V.N. Dang. Methods for building Conditional Probability Tables of Bayesian Belief Networks from limited judgment: An evaluation for Human Reliability Application, Reliability Engineering and System Safety, (2016) Article in Press.

Molla J., Jacobsa J., Kustersb R., et Trienekens, J. Defect detection oriented lifecycle modeling in complex product development. Information and Software Technology, 46 (2004) 665-675.

Moncelet G. Application des Réseaux de Petri à l'évaluation de la sûreté de fonctionnement des systèmes mécatroniques du monde automobile. PhD Thesis, Université Paul Sabatier, Toulouse, octobre (1998). 
G. Habchi and C. Barthod, An overall methodology for reliability prediction of mechatronic systems design with industrial application, Reliability Engineering \& System Safety, 155 (2016), 236-254, doi:10.1016/j.ress.2016.06.013

Mosleh A., Rasmuson D.M., Marshall F.M., Guidelines on Modeling Common-Cause Failures in Probabilistic Risk Assessment, Idaho National Engineering and Environmental Laboratory, University of Maryland, Prepared for U.S. Nuclear Regulatory Commission, NUREG/CR-5485, INEEL/EXT-97-01327, November (1998).

Murthy DNP., M. Rausand, S. Virtanen. Investment in new product reliability. Reliability Engineering and System Safety, 94(10) (2009) 1593-600.

Musa, J., Iannino, A., et Okumoto, K. Software Reliability: Measurement, Prediction, Application. McGraw-Hill, New York and USA, (1987).

Musharraf M., D. Bradbury-Squires, F. Khan, B. Veitch, S. MacKinnon, S. Imtiaz. A virtual experimental technique for data collection for a Bayesian network approach to human reliability analysis, Reliability Engineering and System Safety, 132 (2014) 1-8.

Musharraf M., J. Smith, F. Khan, B. Veitch, S. MacKinnon. Assessing offshore emergency evacuation behavior in a virtual environment using a Bayesian Network approach, Reliability Engineering and System Safety, (2016). Article in Press.

Ollero A., Boverie S., Goodall R., Sasiadek J., Erbe H., Zuehlke D. Mechatronics, robotics and components for automation and control: IFAC milestone report. Annual Reviews in Control, 30 (1) (2006) 41-54.

Onwubolu Godfrey, Mechatronics: Principles and Applications, Elsevier Butterworth-Heinemann, (2005).

Pearl J. Causality: Models, Reasoning, and Inference. Cambridge University Press, Cambridge, England, 2000.

Pearl J. Fusion, propagation, and structuring in belief networks. Artificial Intelligence, 29 (1986) 241-288.

Pearl J. Reverend Bayes on inference engines: A distributed hierarchical approach. Proceedings AAAI National Conference on AI, (1982) 133-136.

Peng W., H-Z. Huang, Y. Li, M.J. Zuo, M. Xie. Life cycle reliability assessment of new products - A Bayesian model updating approach. Reliability Engineering and System Safety, 112 (2013) 109-119.

Rausand M. and A. Høyland, System Reliability Theory: Models, Statistical Methods, and Applications, third ed. Wiley-IEEE, Nov. (2003).

Rieuneau F. Sûreté de fonctionnement en phase de développement des systèmes embarqués automobiles. In Integrated Logistics \& Concurrent Engineering, Montpellier, (1993).

Rutledge, P.J. and Mosleh, A., Dependent-Failures in Spacecraft: Root Causes, Coupling Factors, Defenses, and Design Implications, Proceedings of the Annual Reliability and Maintainability Symposium, IEEE, (1995).

Sadou N. Aide à la conception des systèmes embarqués sûrs de fonctionnement. PhD Thesis, Automatique. INSA de Toulouse, (2007).

Sahner R.A., K.S. Trivedi, A. Puliafito, Performance and Reliability Analysis of Computer Systems: An Examplebased Approach Using the SHARPE Software Package, Kluwer Academic Publishers, Dordrecht, (1996).

Sanna Lahokallio, Kirsi Saarinen-Pulli, Laura Frisk. Effects of different test profiles of temperature cycling tests on the reliability of RFID tags. Microelectronics Reliability, 55(1) (2015) 93-100.

Schoenig R. Définition d'une méthodologie de conception des systèmes mécatroniques sûrs de fonctionnement. PhD thesis, Institut National Polytechnique de Lorraine, (2004).

Schoenig R., Aubry J.-F., Cambois T., Hutinet T. An aggregation method of Markov graphs for the reliability analysis of hybrid systems. Reliability Engineering \& System Safety, 91(2) (2006) 137-148.

Shetty D., Kolk R. Mechatronic Systems Design. PWS Publishing Company, USA, (1997).

Swain A, H. Guttman. Handbook of human reliability analysis with emphasis on nuclear power plant applications. Albuquerque: Sandia National Laboratories; (1983) NUREG/CR-1278, USNRC.

Tollenaere M. Conception de produits mécaniques - méthodes, modèles et outils. Hermes, (1998).

Trivedi K.S., Probability and Statistics with Reliability, Queuing and Computer Science Applications, PrenticeHall, Englewood Cliffs, NJ, (1982).

Turki S. Ingénierie système guidée par les modèles : Application du standard IEEE 15288, de l'architecture MDA et du langage SysML à la conception des systèmes mécatroniques. Software Engineering. Université du Sud, Toulon Var, (2008).

Villemeur A. Sûreté de fonctionnement des systèmes industriels : fiabilité, facteurs humains, informatisation. Ed Eyrolles, Paris, (1988).

Villemeur A. Sûreté de fonctionnement des systèmes industriels, édition Eyrolles, 03 (1997), ISBN 2-212-016158, disponibilité http://www.eyrolles.com/

Wang C., K.S. Trivedi, Integration of specification form modeling and specification for system design, in: Proceedings of the 14th International Conference Application and Theory of Petri Nets, Lecture Notes in Computer Science, Springer, Berlin, 691 (1993) 473-492.

Yaskawa-Electric C. (1969). http://www.yaskawa.co.jp/en/company/rekisi.htm

Yeong K. Kim, Hwang Do Soon. PBGA packaging reliability assessments under random vibrations for space applications. Microelectronics Reliability 55(1) (2015) 172-179.

Zhitao Liu, Cher Ming Tan, Feng Leng, A reliability-based design concept for lithiumion battery pack in electric vehicles, Reliability Engineering and System Safety, (2014), http://dx.doi.org/10.1016/j.ress.2014.10.010 
G. Habchi and C. Barthod, An overall methodology for reliability prediction of mechatronic systems design with industrial application, Reliability Engineering \& System Safety, 155 (2016), 236-254, doi:10.1016/j.ress.2016.06.013

Ziegler C. Sûreté de fonctionnement d'architectures informatiques embarquées sur automobile. PhD thesis, LAAS, Toulouse, (1996). 